\title{
Detection of human cytomegalovirus in medulloblastomas reveals a potential therapeutic target
}

\author{
Ninib Baryawno, ${ }^{1}$ Afsar Rahbar, ${ }^{2}$ Nina Wolmer-Solberg, ${ }^{2}$ Chato Taher, ${ }^{2}$ Jenny Odeberg, ${ }^{2}$ \\ Anna Darabi, ${ }^{3}$ Zahidul Khan, ${ }^{2}$ Baldur Sveinbjörnsson, ${ }^{1,4}$ O.-M. FuskevÅg, ${ }^{5}$ \\ Lova Segerström, ${ }^{1}$ Magnus Nordenskjöld, ${ }^{6}$ Peter Siesjö, ${ }^{3}$ Per Kogner, ${ }^{1}$ \\ John Inge Johnsen, ${ }^{1}$ and Cecilia Söderberg-Nauclér ${ }^{2}$
}

\begin{abstract}
${ }^{1}$ Karolinska Institutet, Department of Women's and Children's Health, Childhood Cancer Research Unit, Stockholm, Sweden. ${ }^{2}$ Karolinska Institutet, Department of Medicine Solna, Experimental Cardiovascular Research Unit, Center for Molecular Medicine, Karolinska University Hospital, Stockholm, Sweden. ${ }^{3}$ Department of Clinical Sciences, Glioma Immunotherapy Group, The Rausing Laboratory, Division of Neurosurgery, Lund University, Lund, Sweden. ${ }^{4}$ Division of Immunology, IMB, University of Tromsö, Tromsö, Norway. ${ }^{5}$ Department of Clinical Pharmacology, University Hospital of North Norway, Tromsö, Norway. ${ }^{6}$ Department of Molecular Medicine and Surgery, Karolinska Institutet, Stockholm, Sweden.
\end{abstract}

\begin{abstract}
Medulloblastomas are the most common malignant brain tumors in children. They express high levels of COX-2 and produce $\mathrm{PGE}_{2}$, which stimulates tumor cell proliferation. Human cytomegalovirus (HCMV) is prevalent in the human population and encodes proteins that provide immune evasion strategies and promote oncogenic transformation and oncomodulation. In particular, HCMV induces COX-2 expression; STAT3 phosphorylation; production of $\mathrm{PGE}_{2}$, vascular endothelial growth factor, and IL-6; and tumor formation in vivo. Here, we show that a large proportion of primary medulloblastomas and medulloblastoma cell lines are infected with HCMV and that COX-2 expression, along with $\mathrm{PGE}_{2}$ levels, in tumors is directly modulated by the virus. Our analysis indicated that both HCMV immediate-early proteins and late proteins are expressed in the majority of primary medulloblastomas. Remarkably, all of the human medulloblastoma cell lines that we analyzed contained HCMV DNA and RNA and expressed HCMV proteins at various levels in vitro. When engrafted into immunocompromised mice, human medulloblastoma cells induced expression of HCMV proteins. HCMV and COX-2 expression correlated in primary tumors, cell lines, and medulloblastoma xenografts. The antiviral drug valganciclovir and the specific COX-2 inhibitor celecoxib prevented HCMV replication in vitro and inhibited $\mathrm{PGE}_{2}$ production and reduced medulloblastoma tumor cell growth both in vitro and in vivo. Ganciclovir did not affect the growth of HCMV-negative tumor cell lines. These findings imply an important role for HCMV in medulloblastoma and suggest HCMV as a novel therapeutic target for this tumor.
\end{abstract}

\section{Introduction}

Medulloblastomas are molecularly and clinically diverse tumor types that together encompass the most frequent malignant brain tumors in children (1). Despite intensive multimodal therapy, survival in high-risk patients is still poor, and long-term survivors frequently experience physical and neuropsychological sequelae $(2,3)$, underscoring the need for new therapeutic options. Although medulloblastomas contain significantly fewer mutations than adult cancers (4), specific subsets have been identified, and aberrations of significant developmental pathways, including the Hedgehog and Wnt pathways, as well as frequent mutations of the MLL family genes have been described. However, since many medulloblastomas have no apparent mutations of any known cancer gene, it has been suggested that epigenetic changes also may be responsible for tumor initiation (4). Hence, additional etiological factors clearly connected to medulloblastoma development remain to be identified.

HCMV DNA and proteins are found in tumors of various origins, including $90 \%-100 \%$ of glioblastomas and prostate, breast, and

Authorship note: Nina Wolmer-Solberg, Chato Taher, and Jenny Odeberg contributed equally to this work. John Inge Johnsen and Cecilia Söderberg-Nauclér share senior authorship.

Conflict of interest: The authors have declared that no conflict of interest exists. Citation for this article: J Clin Invest. 2011;121(10):4043-4055. doi:10.1172/JCI57147. colon cancers (5-7). This virus is not considered to be oncogenic; rather, its potential role in cancer seems to be oncomodulatory (8). Its 230 -kbp genome has 252 open reading frames and encodes approximately 200 proteins, of which only about 50 are known to be essential for viral replication. Hence, the vast majority of HCMV proteins fulfill other functions in the viral life cycle and affect cellular and immunological functions relevant to tumor biology and immune surveillance. HCMV proteins control telomerase activity, cellular differentiation, proliferation (through specific effects on the cell cycle), apoptosis, epigenetic functions, migration, and angiogenesis (8-10). HCMV induces inflammation, but in parallel, it escapes immune recognition $(8,10)$. These tumor-promoting functions of HCMV proteins, together with the detection of HCMV DNA and proteins in tumors of different origins, suggest that HCMV has a pivotal, hitherto unknown role in the tumorigenesis of certain cancers (8).

The inflammatory mediator $\mathrm{PGE}_{2}$, a COX-2 metabolite implicated as a growth factor for tumor cells, drives cancer progression through its ability to stimulate cell proliferation, promote angiogenesis and invasion, inhibit apoptosis, and suppress immune responses (11-13). For unknown reasons, many tumors, including medulloblastomas, express $\mathrm{COX}-2$, and inhibition of $\mathrm{PGE}_{2}$ synthesis with nonsteroidal antiinflammatory drugs induces apoptosis in medulloblastoma cell lines and significantly inhibits the growth 
Table 1

IE and late protein expression in medulloblastoma primary tumors

\begin{tabular}{|c|c|c|c|c|c|c|c|c|c|}
\hline Sample & Diagnosis & Age at surgery (yr) & Sex & Risk group & Outcome & Survival (mo) & Metastasis & IE & Late \\
\hline 1 & MB & 7 & M & $\mathrm{HR}$ & NED & $178+$ & Yes & $4+$ & $1+$ \\
\hline 2 & MB & 8 & $\mathrm{~F}$ & SR & NED & $152+$ & No & $3+$ & $1+$ \\
\hline 3 & sPNET & 8 & $\mathrm{~F}$ & HR & NED & $158+$ & No & $4+$ & $4+$ \\
\hline 4 & MB & 8 & M & SR & DOD & 108 & No & $4+$ & neg \\
\hline 5 & SPNET & 3 & M & $\mathrm{HR}$ & DOD & 111 & No & $4+$ & $1+$ \\
\hline 6 & MB & 8 & M & SR & DOD & 31 & No & $1+$ & $1+$ \\
\hline 7 & MB & 2 & M & $\mathrm{HR}$ & NED & $149+$ & No & $4+$ & $3+$ \\
\hline 8 & MB & 5 & $\mathrm{~F}$ & $\mathrm{HR}$ & NED & $143+$ & Yes & $3+$ & $3+$ \\
\hline 9 & MB & 7 & M & SR & NED & $138+$ & No & neg & neg \\
\hline 10 & MB & 11 & $\mathrm{~F}$ & HR & NED & $118+$ & Yes & $3+$ & $3+$ \\
\hline 11 & MB & 1 & $\mathrm{~F}$ & SR & NED & $117+$ & No & $1+$ & $1+$ \\
\hline 12 & MB & 4 & M & SR & NED & $113+$ & No & $2+$ & neg \\
\hline 13 & MB & 8 & $\mathrm{~F}$ & SR & NED & $98+$ & No & $4+$ & $3+$ \\
\hline 14 & MB & 1 & $\mathrm{~F}$ & $\mathrm{HR}$ & NED & $87+$ & No & $4+$ & $3+$ \\
\hline 15 & MB & 4 & M & SR & NED & $85+$ & No & $3+$ & $3+$ \\
\hline 16 & MB & 8 & $\mathrm{~F}$ & SR & NED & $84+$ & No & $4+$ & $3+$ \\
\hline 17 & MB & 7 & M & $\mathrm{HR}$ & DOD & 3 & Yes & $1+$ & neg \\
\hline 18 & MB & 11 & M & $H R$ & NED & $70_{+}$ & Yes & $1+$ & neg \\
\hline 19 & MB & 3 & $\mathrm{~F}$ & $\mathrm{HR}$ & DOD & 19 & No & neg & neg \\
\hline 20 & MB & 25 & $\mathrm{~F}$ & SR & NED & $64+$ & No & $3+$ & $1+$ \\
\hline 21 & MB & 7 & M & $\mathrm{HR}$ & NED & $50+$ & Yes & $2+$ & neg \\
\hline 22 & MB & 7 & M & SR & DOD & 34 & No & $4+$ & $1+$ \\
\hline 23 & SPNET & 11 & $\mathrm{~F}$ & SR & NED & $166+$ & No & $4+$ & $1+$ \\
\hline 24 & $\mathrm{MB}$ & 23 & M & $S R$ & DOD & 27 & No & $3+$ & $1+$ \\
\hline 25 & MB & 27 & M & SR & NED & $150_{+}$ & No & $3+$ & $1+$ \\
\hline 26 & MB & 25 & M & SR & NED & $135+$ & No & $4+$ & neg \\
\hline 27 & MB/sPNET & 47 & $\mathrm{~F}$ & $\mathrm{HR}$ & DOD & 44 & Yes & $1+$ & $1+$ \\
\hline 28 & $\mathrm{MB}$ & 30 & M & SR & NED & $98+$ & No & neg & neg \\
\hline 29 & MB & 19 & $\mathrm{~F}$ & SR & DOD & 0 & No & $1+$ & $1+$ \\
\hline 30 & MB & 19 & M & $\mathrm{HR}$ & DOD & 23 & Yes & neg & neg \\
\hline 31 & MB & 12 & $\mathrm{~F}$ & SR & DOD & 54 & No & $3+$ & $3+$ \\
\hline 32 & MB & 12 & M & SR & NED & $17+$ & No & $3+$ & $2+$ \\
\hline 33 & MB & 10 & M & SR & NED & $6+$ & No & $4+$ & $3+$ \\
\hline 34 & MB & 9 & M & SR & NED & $12+$ & No & $4+$ & $2+$ \\
\hline 35 & MB & 8 & M & SR & NED & $12+$ & No & $3+$ & $2+$ \\
\hline 36 & MB/sPNET & 4 & $\mathrm{~F}$ & $\mathrm{HR}$ & DOD & 5 & Yes & $4+$ & $4+$ \\
\hline 37 & MB & 2 & M & $\mathrm{HR}$ & DOD & 30 & Yes & $3+$ & $3+$ \\
\hline
\end{tabular}

MB, medulloblastoma; sPNET, Supratentorial primitive neuroectodermal tumor; HR, high risk; SR, standard risk; NED, no evidence of disease; DOD, dead of disease; neg, negative.

of medulloblastomas in vivo (14). Aspirin reduces the incidence and growth of various cancer forms in animal models $(15,16)$, an effect that may be mediated at least in part by inhibition of COX-2 enzymes, resulting in decreased production of prostaglandins and other inflammatory mediators. In clinical trials, aspirin given daily to prevent vascular events for at least 4 years reduced death from different forms of cancer both during and after the trials (17). In clinical studies, nonspecific and specific COX-2 inhibitors have shown promise as anticancer agents $(16,18-20)$.

Interestingly, the HCMV protein US28, a constitutively active chemokine receptor homolog, induces COX-2 expression and results in STAT3 phosphorylation, which increases production of vascular endothelial growth factor and IL- 6 as well as tumor formation in vivo (21). Both aspirin and selective COX-2 inhibitors efficiently prevent viral production, which is partly dependent on $\mathrm{PGE}_{2}(22,23)$. Transgenic mice that express US28 in intestinal epithelial cells exhibit a hyperplastic intestinal epithelium and tumor development. US28 expression in intestinal epithelial cells inhibits glycogen synthase- $3 \beta$ (GSK-3 $\beta$ ) function, promotes accumulation of $\beta$-catenin, and increases expression of Wnt target genes involved in the control of cell proliferation (24); these findings provide a direct molecular link between this HCMV protein and oncogenesis. Moreover, we recently demonstrated that the HCMV protein IE72 induces telomerase activity, which is likely another important event in tumor transformation (25).

In this study, we examined the prevalence of HCMV in medulloblastomas. We also assessed the connection between HCMV and COX-2 expression in tumors and sought to determine whether inhibition of viral replication with antiviral treatment and COX-2 inhibition affects tumor growth in vitro and in vivo.

\section{Results}

High prevalence of HCMV in primary medulloblastomas, medulloblastoma cell lines, and medulloblastoma xenografts. Of the 37 primary medullo- 

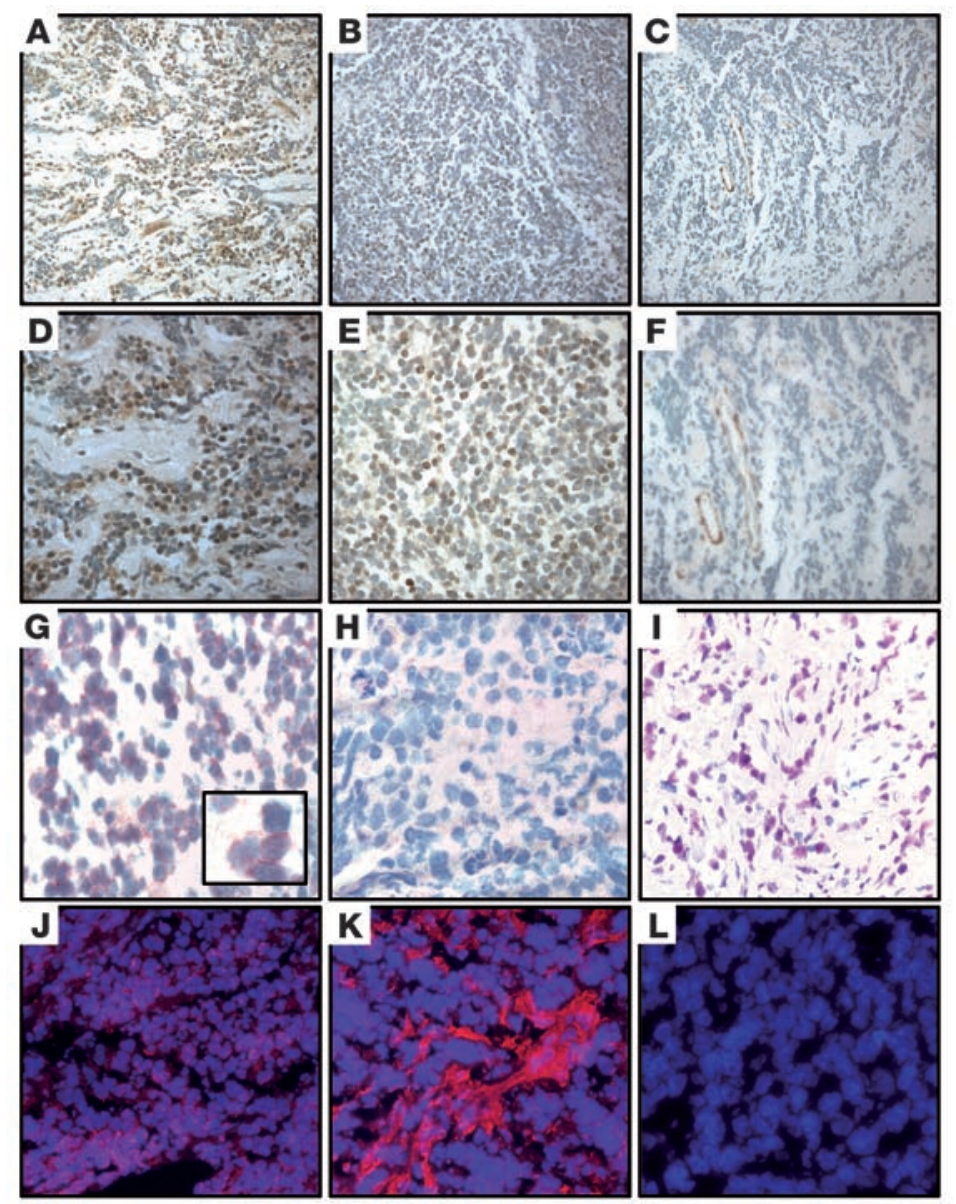

M

M HCMV protein expression
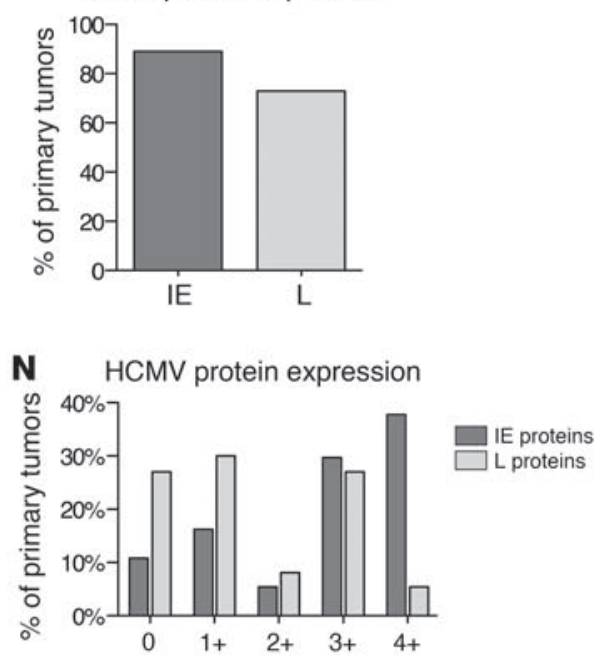

O



UL83

\section{Figure 1}

Detection of HCMV DNA and proteins in a majority of primary medulloblastoma tissue samples. (A-F) Immunohistochemical assessment of HCMV IE ( $\mathbf{A}$ and $\mathbf{D})$ and late ( $\mathbf{B}$ and $\mathbf{E})$ proteins in primary medulloblastomas; $\alpha$-actin served as an isotype control antibody (C and $\mathbf{F})$. Original magnification, $\times 20(\mathbf{A}-\mathbf{C})$ and $\times 40(\mathbf{D}-\mathbf{F})$. (G-I) Confirmation of immunohistochemical findings by in situ hybridization. (G) HCMV DNA. (H) Negative control. (I) Positive control (Alu). Original magnification, $\times 40$, inset, $\times 100$ (G); $\times 40$ (H); $\times 20$ (I). (J-L) Indirect immunofluorescence staining for HCMV IE $(\mathbf{J})$ and late $(\mathbf{K})$ antigens in frozen sections of a primary medulloblastoma, and isotype control for immunofluorescence (L). Original magnification, $\times 20(\mathbf{J}-\mathbf{L})$. (M) Quantification of HCMV expression in medulloblastomas positive for HCMV IE and late proteins. (N) HCMV expression graded 1-4 according to the percentage of HCMV-positive cells in 37 primary medulloblastoma tissue samples (see Methods for details). L, late. (0) Flow cytometric analysis of HCMV UL83 expression in two primary medulloblastomas (M2 and M3). Isotype antibodies served as a negative control.

blastomas we examined for HCMV, 34 (92\%) expressed immediateearly (IE) proteins and 27 (73\%) expressed late proteins (Table 1). The IE and late proteins were widely expressed in cells within the tumor (Figure 1), as determined by immunohistochemistry $(n=37$, Figure 1, A, B, D, E, M, and N) or indirect immunofluorescence $(n=6$, Figure $1, \mathrm{~J}, \mathrm{~K}$, and $\mathrm{L})$ in frozen tissue sections. Detection of IE proteins with two different IE-specific antibodies resulted in nuclear (Figure 1) or nuclear/cytoplasmic (see below) staining patterns. In situ hybridization confirmed the presence of HCMV in primary medulloblastomas (Figure 1, G-I). Flow cytometric analysis of these tumors revealed expression of HCMV IE and UL83 (pp65 in Figure 1O) proteins in $90 \%-95 \%$ of the cells $(n=2)$. Six available frozen tissue samples were confirmed to contain HCMV IE, pp150, and gB DNA and IE and gB RNA by TaqMan PCR (data not shown). Sequencing of the PCR products revealed that the HCMV genome in medulloblastoma cell lines was distinctly dif- ferent from that in 4 commonly used laboratory strains (Merlin, AD169, TB40E, and VR1814; data not shown), which excluded the possibility of contamination.

Next, we analyzed 8 human medulloblastoma cell lines (D324 MED, D283 MED, UW228-3, MEB-MED-8A, D458 MED, PFSK-1, D384 MED, and D425 MED) for HCMV DNA and RNA by PCR. Surprisingly, HCMV IE and pp150 DNA and IE and gB RNA were detected at low levels in all 8 cell lines (Supplemental Table 1; supplemental material available online with this article; doi:10.1172/ JCI57147DS1). FISH analyses with a probe utilizing the whole HCMV genome in bacterial artificial chromosome clones revealed HCMV DNA in medulloblastoma cells and in HCMV-infected (AD169) MRC-5 human fibroblasts, but not in K562 cells (control human chronic myelogenous leukemia cells; Figure 2A). To examine whether the viral genome was integrated in human chromosomes, we performed FISH analyses on colcemid-treated D324 
A
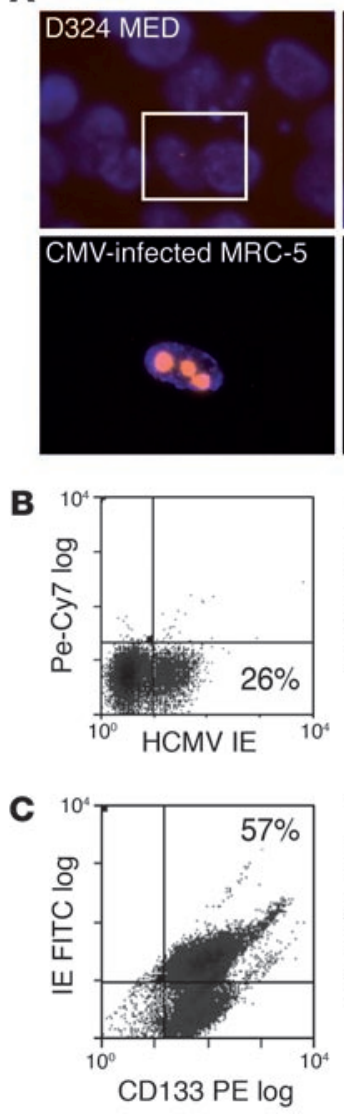
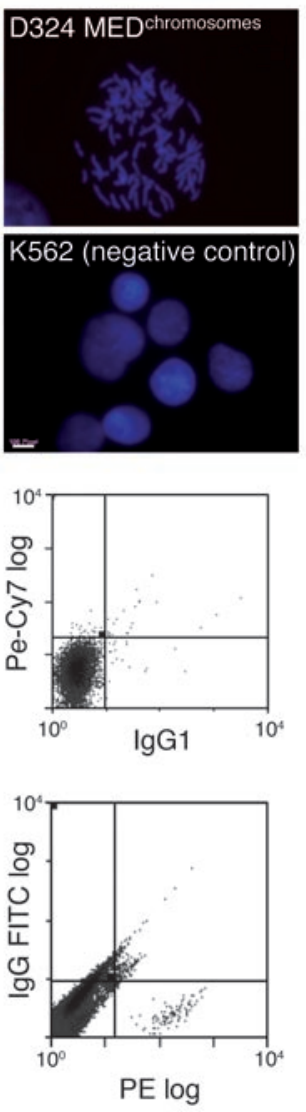

D
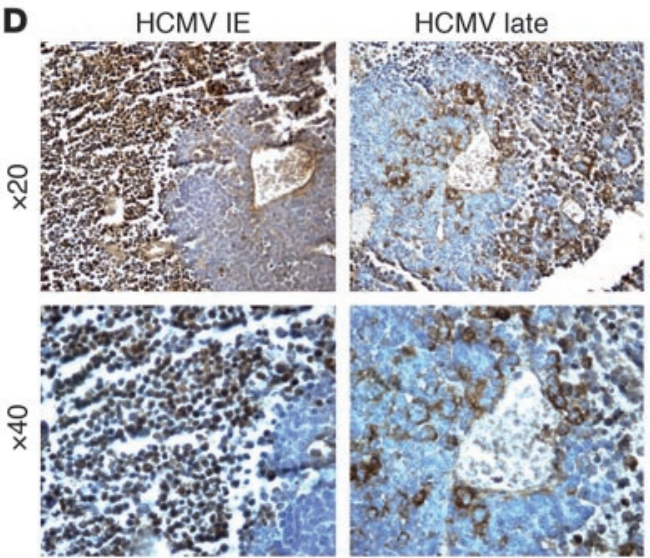

$\alpha$-Actin (isotype control)

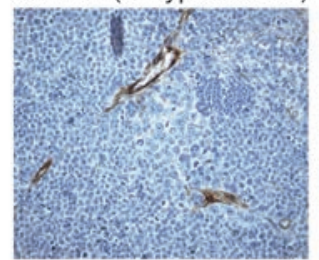

Negative control

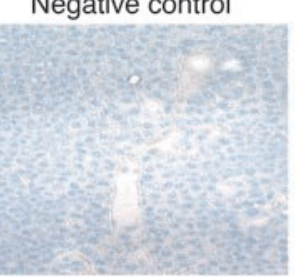

Figure 2

Detection of HCMV DNA and proteins in medulloblastoma cell lines and human medulloblastoma xenografts. (A) FISH analysis showing the presence of HCMV DNA (red) in colcemid-treated D324 MED cells and HCMV-infected (AD169) MRC-5 cells in metaphase, but not in uninfected K562 cells. (B) Flow cytometric analysis of D324 MED cells stained for the HCMV IE antigen or an isotype control antibody (IgG1). (C) Flow cytometric analysis of D283 MED cells double-stained for HCMV IE and CD133. (D) Detection of HCMV IE and late proteins in established human medulloblastoma xenografts in NMRI nu/nu mice. $\alpha$-Actin served as an isotype control.

MED cells. No sign of integration of HCMV DNA in chromosomes was observed in metaphase cells (Figure 2A).

Further analysis by flow cytometry revealed HCMV IE and pp 65 protein expression in 9\%-39\% of the cells; D324 MED cells stained for IE are shown in Figure 2B, and UW228-3 cells stained for IE and pp65 are shown in Figure 3B. On different sampling occasions over a 12-month period, HCMV proteins were expressed in $0.2 \%-75 \%$ of cells in individual medulloblastoma cell lines. Given this consistent presence of viral DNA, we hypothesized that HCMV resides in cancer stem cells. To test this hypothesis, we double stained the medulloblastoma cell line D283 MED for CD133 (a stem cell marker) and HCMV IE proteins. 57\% of the CD133-positive cells coexpressed HCMV IE proteins (Figure 2C). When D283 MED cells were xenografted subcutaneously in NMRI $n u / n u$ mice, HCMV protein expression distinctly increased, and a majority of the tumor cells were positive for HCMV IE proteins. While IE protein expression was diffuse in the xenografts, HCMV late protein expression was distinctly located adjacent to vessels (Figure 2D).

$H C M V$-positive medulloblastoma cells express COX-2. Since medulloblastomas express COX-2 and HCMV induces expression of COX-2 $(14,21)$, we investigated whether HCMV protein expression correlated with COX-2 expression in tumor cells. In frozen tissue sections of primary medulloblastomas, HCMV protein expression correlated with COX-2 expression (Figure 3A). IE proteins were expressed in both the nucleus and cytoplasm of tumor cells. In medulloblastoma cell lines, cells positive for the HCMV IE pp65 also expressed COX-2 (Figure 3B). HCMV and COX-2 expression also correlated in human medulloblastoma xenografts in mice (data not shown). These observations imply that HCMV may control the expression of COX-2 in medulloblastomas.

HCMV infection induces COX-2 expression and $P G E_{2}$ synthesis in medulloblastoma cells. HCMV induces COX-2 expression in fibroblasts and epithelial and smooth muscle cells $(22,23)$. We hypothesized that HCMV also regulates COX-2 expression in medulloblastomas. In vitro infection (superinfection) of medulloblastoma cells (D324 MED) with HCMV resulted in increased IE RNA expression at 3 hours after infection (relative mRNA expression, 0.04296, $n=3$ in duplicate) that greatly increased at 6-72 hours after infection (Figure 4A). The late HCMV pp150 RNA was detectable at 3 hours after infection (relative mRNA expression, $0.00316, n=3$ in duplicates), and was greatly increased at 24 hours after infection (Figure 4A). Both IE and pp150 were detectable at low levels in the uninfected cells (mean relative mRNA expression, 0.0000322 and 0.00000132 , respec- 
A
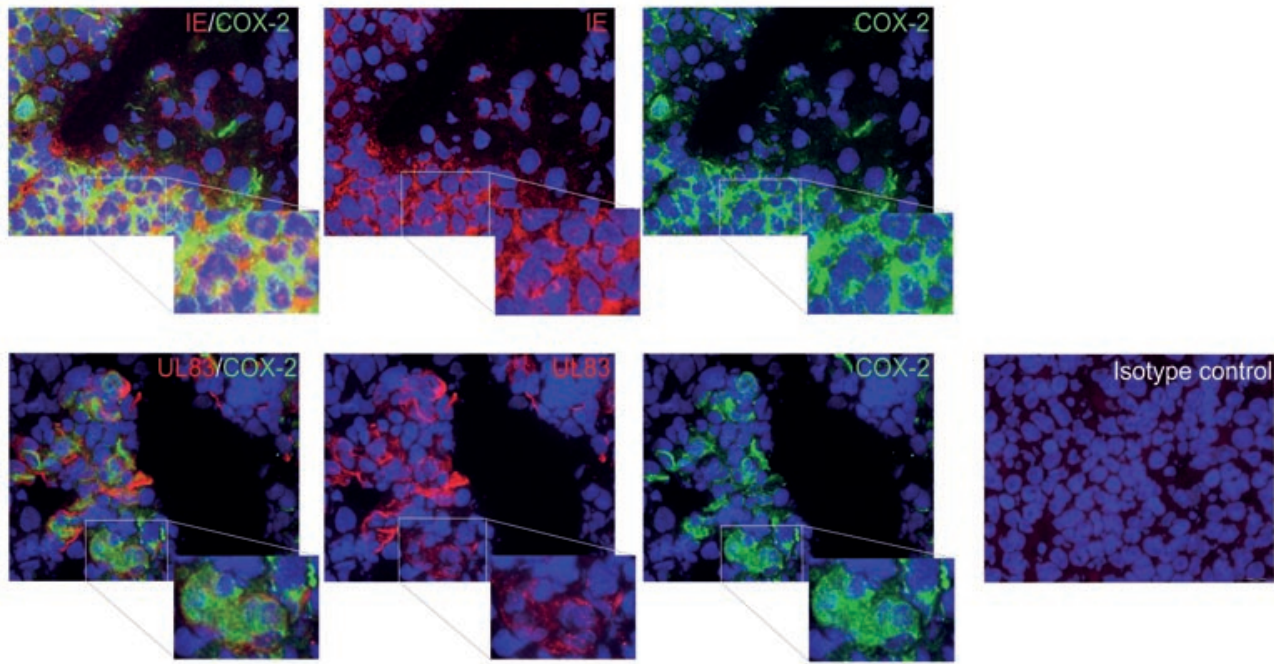

B
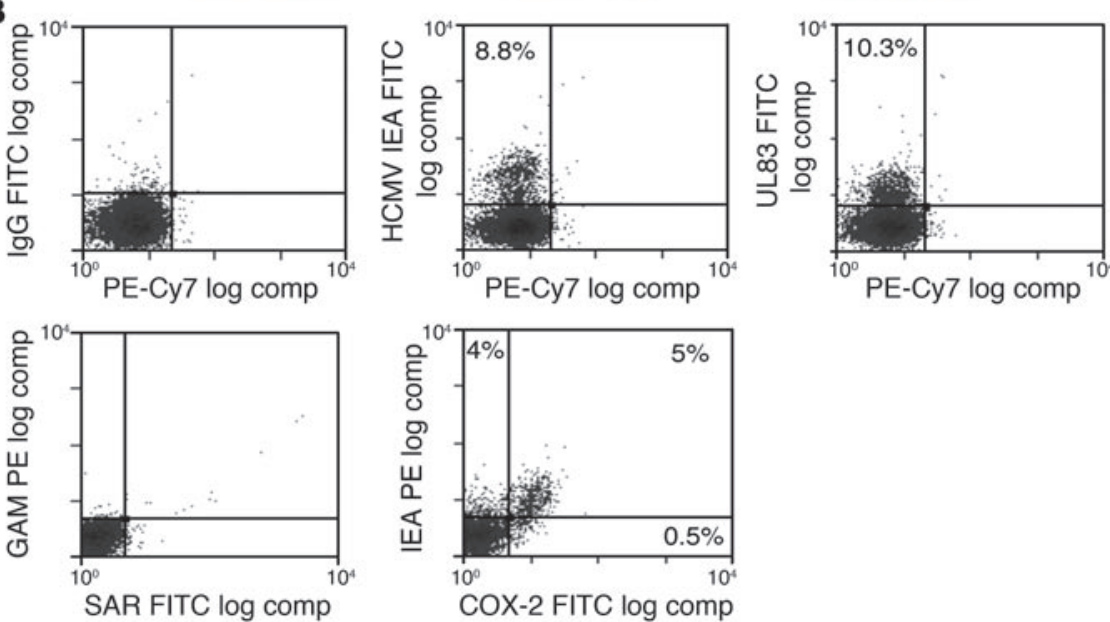

\section{Figure 3}

COX-2 expression in primary medulloblastomas and cell lines is restricted to positivity for HCMV proteins. The HCMV protein UL83 and COX-2 are coexpressed in primary medulloblastomas, as shown by (A) immunohistochemical double staining for COX-2 (green) and either HCMV IE1/IE2 protein (red) or HCMV protein UL83 (red). Nuclei were stained with DAPI (blue). Isotype antibodies served as negative control. Original magnification, $\times 40$. (B) Flow cytometric analysis of UW228-3 cells. Top row: Cells were stained for isotype control (IgG1), IE antigen (IEA), or UL83. Bottom row: Cells were stained with the secondary antibodies goat anti-mouse (GAM) and swine anti-rabbit (SAR) (negative control) or for IE antigen and COX-2. tively; $n=3 ; 7$ time points in duplicate). Interestingly, expression of COX-2 mRNA was already increased at 1 and 3 hours after infection in cells infected with both HCMV- and UV-treated virus inoculum (Figure 4A), before induced IE expression was detected. Also, an increased level of the COX-2 protein was detectable at 3 hours after infection (Figure 4B). As US28 has been demonstrated to induce COX-2 expression, we examined whether US28 was expressed at early time points after infection. We found that US28 mRNA could be detected in cells already at 15 minutes after infection: low US28 mRNA levels were also detected in UVHCMV-infected cells. This was consistent with the increased expression of COX-2 mRNA observed in both HCMV- and UVHCMV-infected cells at 1 and 3 hours after infection. At 3 days after infection, HCMV had significantly increased $\mathrm{PGE}_{2}$ synthesis (Figure 4C), which was significantly reduced when D324 MED cells were treated with ganciclovir, celecoxib, or both drugs (Figure 4D); this was consistent with the detection of COX-2 mRNA in HCMV-infected but not UV-HCMV-infected cells at 72 hours after infection (Figure 4A).

Antiviral treatment and COX-2 inhibition significantly inbibit medulloblastoma growth in vitro and in vivo. As HCMV appears to be present in a majority of medulloblastoma tumors, and viral mechanisms control COX-2 expression, we sought to test whether inhibition of viral replication by antiviral drugs or COX-2 inhibitors affects tumor growth in vitro and in vivo. Both specific and nonspecific COX-2 inhibitors can prevent virus-mediated accumulation of $\mathrm{PGE}_{2}$ and efficiently inhibit viral production, as viral replication appears to be dependent on $\mathrm{PGE}_{2}(22,23)$. Therefore, we examined whether ganciclovir, which targets the DNA polymerase during HCMV replication, or the COX-2 inhibitor celecoxib, which prevents $\mathrm{HCMV}$ replication by decreasing $\mathrm{PGE}_{2}$ levels, affects medulloblastoma growth in vitro.

In clonogenic assays with the native medulloblastoma cells, treatment with increasing concentrations of ganciclovir reduced the clonogenic capacity of D324 MED $(P<0.0001)$, D283 MED $(P<0.0001)$, and UW228-3 $(P<0.001$, Figure $5 A)$. Since none of the screened medulloblastoma cell lines were HCMV negative, we tested the effect of ganciclovir on the growth of two tumor cell lines that were negative for HCMV by PCR and flow cytometry (data not shown): PC-3 (established from a bone metastasis of a grade IV prostatic adenocarcinoma) and BxPC-3 (established from a pancreatic adenocarcinoma). Treatment with increasing concentrations of ganciclovir had no significant effect on the clonogenic capacity of either cell line in the presence of ganciclovir $(37.5,75$, or $150 \mu \mathrm{M})$ (Figure $5 \mathrm{~A}$ ).

Celecoxib also reduced the clonogenic capacity of D324 MED $(P<0.0001)$ and D283 MED $(P<0.0001)$ but not of UW228-3 (Figure $5 \mathrm{~B})$. In combination, valganciclovir and celecoxib significantly reduced the clonogenic capacity of medulloblastoma cell lines 

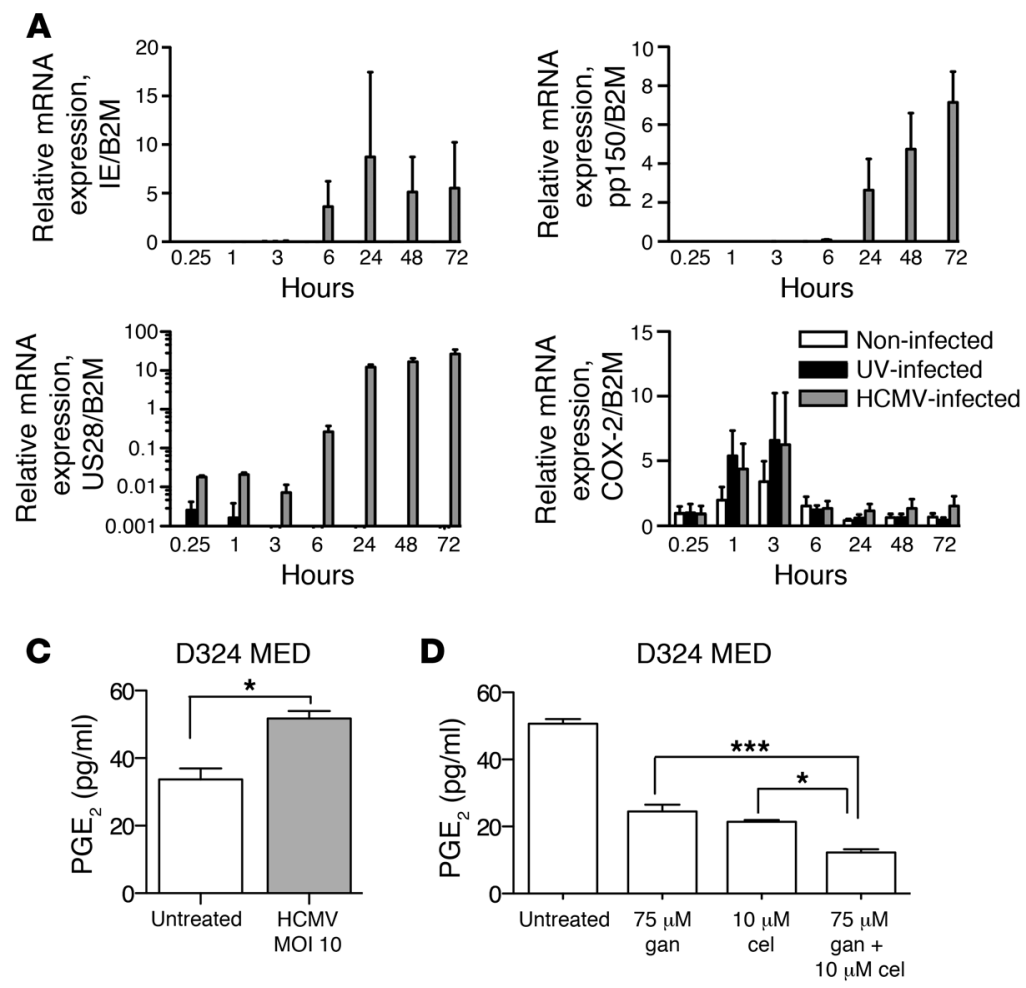

B

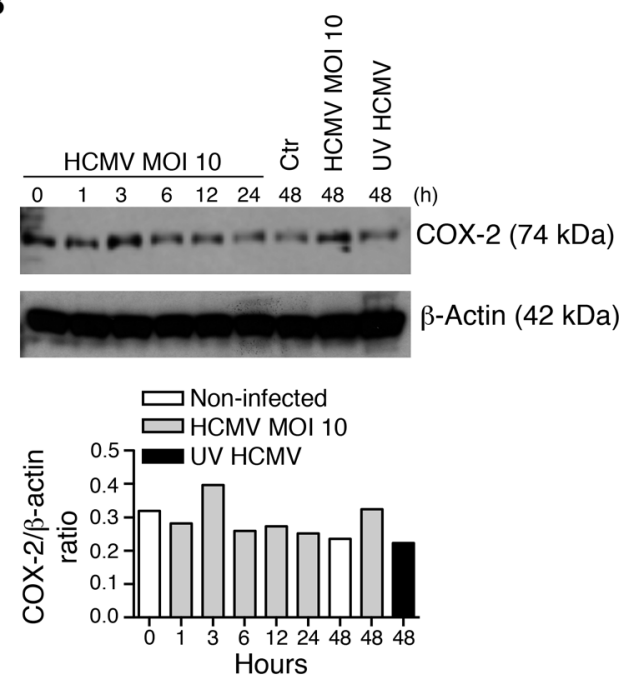

Figure 4

HCMV induces COX-2 expression and $\mathrm{PGE}_{2}$ synthesis in medulloblastoma cells. (A) HCMV IE mRNA, US28 mRNA, and low levels of the late gene pp150 mRNA were expressed in D324 MED cells after in vitro infection with HCMV VR1814 as shown by quantitative PCR at 15 minutes to 72 hours after infection. COX-2 mRNA was detected when US28 was expressed, but earlier than IE mRNA. (B-D) Superinfection of HCMV VR1814 increases COX-2 expression and PGE 2 levels in D324 MED cells as shown by Western blotting (B). ctr, control. (C) PGE 2 levels measured by ELISA 48 hours after infection with HCMV VR1814. (D) Ganciclovir (gan) and celecoxib (cel) significantly inhibit PGE 2 synthesis in D324 MED cells as measured by $\mathrm{PGE}_{2}$ ELISA. ${ }^{\star} P<0.05$, ${ }^{\star \star \star} P<0.0001$ (1-way ANOVA). Values are mean \pm SD.

compared with single treatments alone (D324 MED, $P<0.0001$; D283 MED, $P<0.0001$; UW228-3, $P<0.001$; Figure 5B). To further test whether ganciclovir had a general cytotoxic effect, we performed survival assays (MTT) in human fibroblasts. At the same concentrations that significantly inhibited the growth of medulloblastoma cells, neither drug alone nor the combinations of the two drugs affected the survival of MRC-5 cells (Figure 5B). These data imply that the antitumor response in HCMV-positive medulloblastoma cell lines reflects a specific antitumor effect involving HCMV rather than cytotoxicity.

To further investigate whether the growth-suppressing effect of ganciclovir and celecoxib is dependent on the presence HCMV in medulloblastoma cells, we treated D283 MED cells with different concentrations of ganciclovir $(37.5,75$, and $150 \mu \mathrm{M})$. After 2 weeks of continuous treatment, viral protein expression in cells treated with $75 \mu \mathrm{M}$ ganciclovir had decreased substantially (data not shown and Figure 6A), but neither HCMV protein expression nor HCMV DNA was completely eliminated (Figure 6A). Although D283 MED cells pretreated with ganciclovir (D283 MEDgan) were able to grow in soft agar, they formed significantly fewer colonies than untreated D283 MED (D283 MED ${ }^{\text {WT }}$ ) cells $(P<0.05$; Figure 6A). The clonogenic capacity of D283 MEDgan cells was not affected by increasing concentrations of ganciclovir or celecoxib but was significantly reduced by the combination of the two drugs (Figure 6A).
In clonogenic assays with HCMV-superinfected medulloblastoma cells, treatment with increasing concentrations of ganciclovir or celecoxib also significantly reduced the tumorigenic capacity of HCMV-D324 MED, HCMV-D283 MED, and HCMV-UW228-3 cells in a dose-dependent manner (Figure 6B). Combining celecoxib with ganciclovir augmented the effect; growth was reduced by $81 \%, 84 \%$, and $97 \%(P<0.0001$, Figure $6 \mathrm{~B})$, respectively, in superinfected cells. Consistent with these observations, valganciclovir and celecoxib alone or in combination also reduced $\mathrm{PGE}_{2}$ production in D324 MED cells (Figure 4D).

To further investigate the therapeutic effects of valganciclovir and celecoxib in vivo, we established a human medulloblastoma xenograft model using D283 MED cells in NMRI $n u / n u$ mice. We first determined the bioavailability of valganciclovir in these mice. After administration of valganciclovir at $100 \mathrm{mg} / \mathrm{kg}$, the plasma ganciclovir concentration was sufficient for a potential therapeutic effect (Figure 7A). To observe a combinatorial effect with celecoxib, we reduced the valganciclovir dose. Mice were randomized to daily treatment for 12 days with oral valganciclovir $(14 \mathrm{mg} / \mathrm{kg}$ twice daily) or oral celecoxib (90 mg/kg once daily), starting at a tumor volume of $0.1 \mathrm{ml}$. The mice were euthanized, and the tumors were collected for analysis. HCMV protein expression in the xenografts was strongly increased compared with that in the cells in culture (Figure 2D). Each drug inhibited the growth of established medulloblastomas by approximately $40 \%$ (valganciclovir, $P<0.0001$; cele- 
A

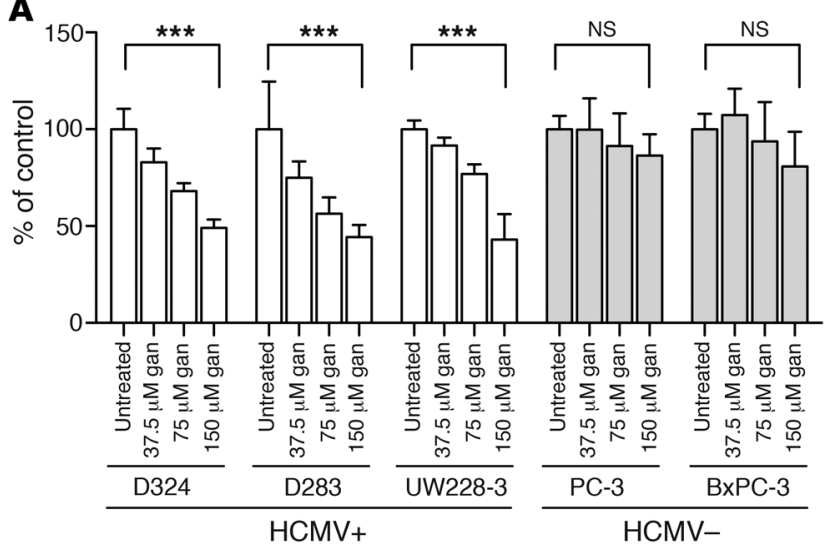

B
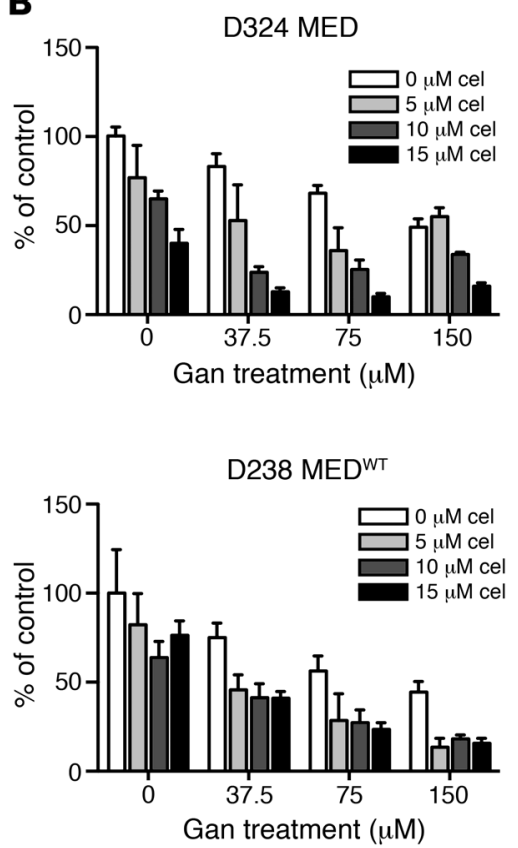

UW228-3
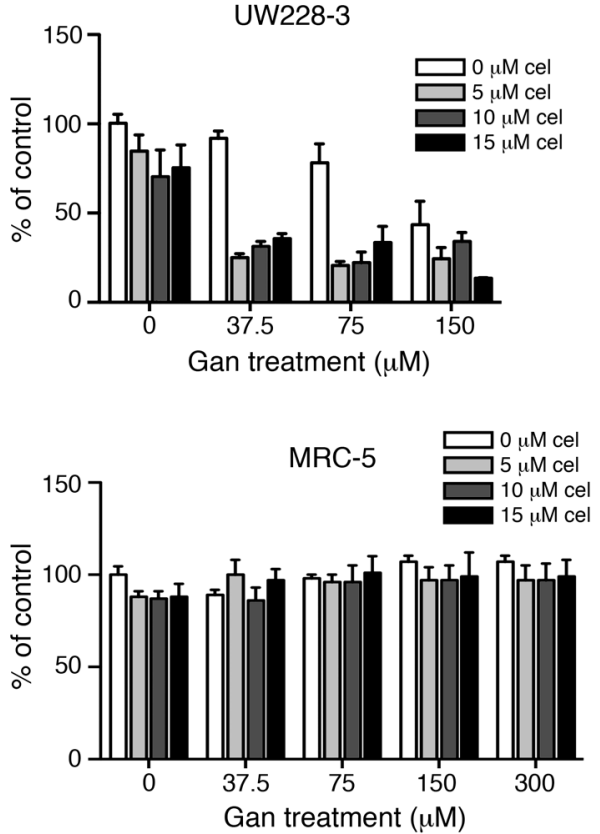

\section{Figure 5}

Ganciclovir and celecoxib significantly impair the growth of medulloblastoma cell lines in vitro. (A) Ganciclovir (gan) significantly inhibits the clonogenic capacity of D324 MED, D283 MED, and UW228-3 cells in a dosedependent manner but has no growth-inhibiting effect on HCMV-negative PC-3 or BxPC-3 cells ${ }^{* *} P<0.0001$ (1-way ANOVA) (B) Ganciclovir significantly augments the growthinhibitory effect of celecoxib in D324 MED, UW228-3, and D283 MED cells. At the same concentrations that significantly inhibited the growth of medulloblastoma cells, neither drug alone nor the combinations of the two drugs affected the survival of MRC- 5 cells in survival assays (MTT) in human MRC- 5 fibroblasts. Values are mean \pm SD. coxib, $P<0.0001$; Figure 7, B and C). In combination, celecoxib and valganciclovir reduced tumor growth by $72 \%$ (tumor volume index [TVI], 3.3 versus 10.3 in untreated controls, $P<0.0001$; Figure $7, \mathrm{~B}$ and $\mathrm{C}$ ). The combined drug regimen reduced the number of clusters positive for HCMV late protein in xenograft tumors by $80 \%(P<0.0001$; Figure $7, \mathrm{D}$ and $\mathrm{E})$.

We also established xenografts of the two HCMV-negative tumor cell lines (PC-3 and BxPC-3) to test the effect of ganciclovir on tumor cell growth. In NMRI $n u / n u$ mice carrying either PC-3 or BxPC-3 xenografts, tumor growth was unaffected by treatment with oral valganciclovir (14 mg/ $\mathrm{kg}$ twice daily) (tumor weight: PC-3, $P=0.4810 ;$ BxPC-3, $P=0.7237$; Figure $7, \mathrm{~F}$ and $\mathrm{G})$.

\section{Discussion}

This study shows that HCMV proteins are expressed in the majority of primary medulloblastoma tissue samples. Surprisingly, HCMV DNA, RNA, and proteins were detected in 8 examined medulloblastoma cell lines, and viral protein expression was highly induced by xenografting of human medulloblastoma cells in vivo. Sequencing of PCR products excluded the possibility that the cells lines were contaminated by a laboratory strain. Targeting of HCMV by antiviral or COX-2-inhibitory drugs with different modes of action on viral replication significantly impaired tumor growth in vivo. These observations imply a persistent source of HCMV in neuroprecursor cells and suggest that the virus has a pathogenetic role in medulloblastoma rather than representing an epiphenomenon. Importantly, our findings also suggest HCMV as a novel therapeutic target for this tumor.

Medulloblastomas can originate from neural precursor cells in the external granule layer in the cerebellum or from cells in the dorsal brainstem (26). Medulloblastoma cells exhibit many characteristics similar to those of progenitor cells of the embryonic brain, further suggesting the presence of a tumor-initiating or cancer stem cell population in these tumors (26). This statement is supported by the clinical presentation and treatment response and by the fact that cells positive for stem cell markers (e.g., CD133 or CD15 in primary medulloblastomas) give rise to new tumors in xenograft models (27, 28). Since HCMV appears to persist for years in laboratory cell lines, the virus is most likely maintained in a stem-like cell phenotype within this population. Indeed, we observed HCMV protein expression 


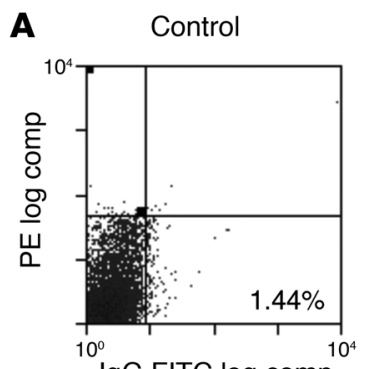

IgG FITC log comp

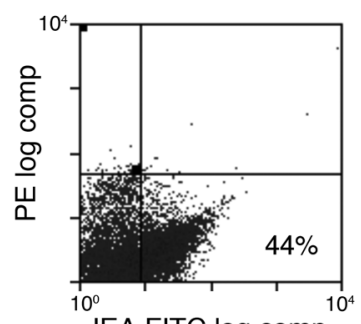

IEA FITC log comp

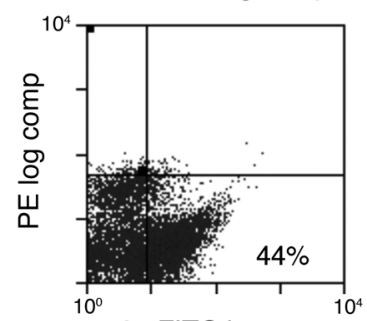

pp65 FITC log comp
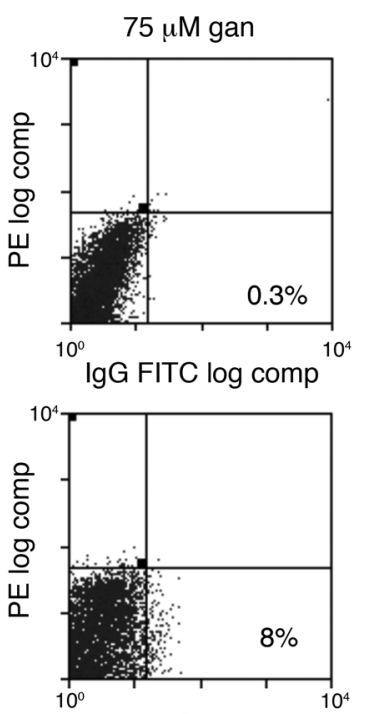

IEA FITC log comp

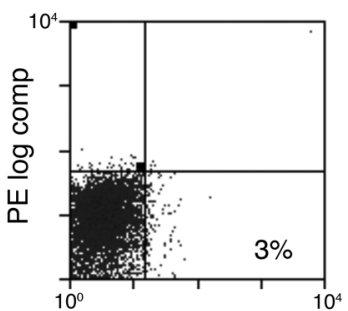

pp65 FITC log comp

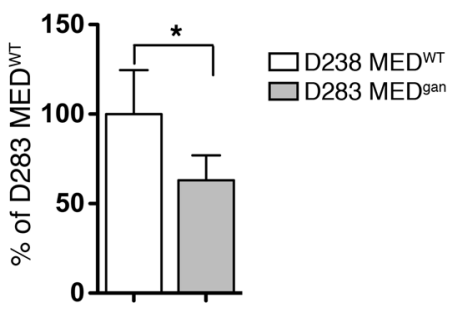

D283 MED ${ }^{\text {gan }}$

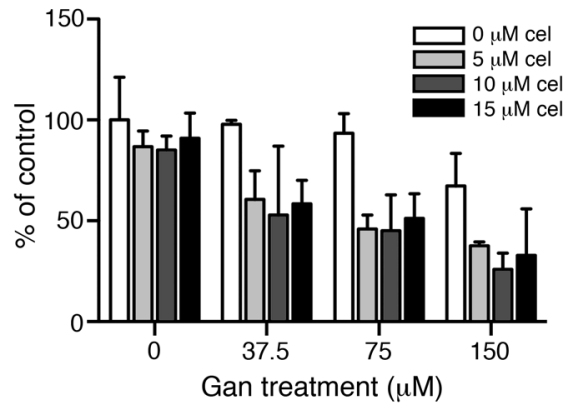

B

D324 MED
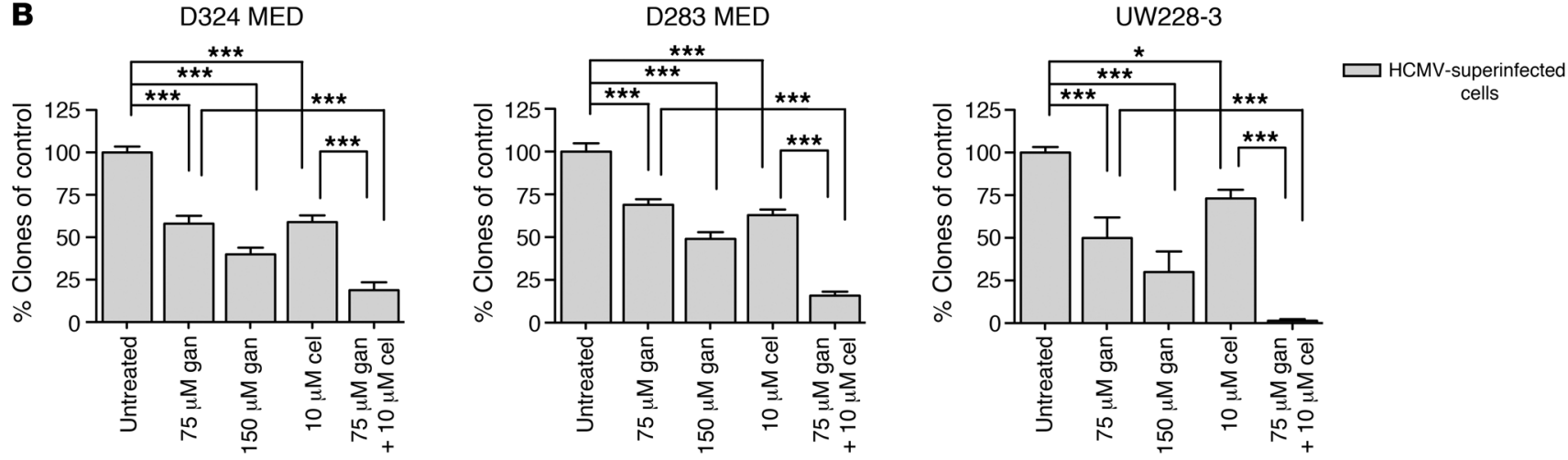

Figure 6

Antiviral treatment reduces CMV protein expression and clonogenic capacity of medulloblastoma cells in vitro. (A) D283 MED cells pretreated with $75 \mu \mathrm{M}$ ganciclovir (D283 MEDgan) exhibited markedly reduced HCMV IE and pp65 protein expression (left panel), had significantly reduced clonogenic capacity $\left({ }^{\star} P<0.05, t\right.$ test; upper-right panel, and were resistant to ganciclovir $(0-150 \mu \mathrm{M})$ or celecoxib treatment but demonstrated reduced clonogenic capacity in treatment with a combination of ganciclovir and celecoxib (right lower panel) (B) Ganciclovir and celecoxib also inhibited the clonogenic capacity of D324 MED, D283 MED, and UW228-3 cells superinfected with HCMV VR1814. ${ }^{*} P<0.05,{ }^{* * *} P<0.0001$ (1-way ANOVA). Values are mean \pm SD.

in 57\% of CD133-positive D283 MED cells. The viral genome did not appear to be integrated into human chromosomes, and we concluded that HCMV integration evidently is not a major event in the medulloblastomas, although it cannot be excluded in single cells.

HCMV can infect neuronal progenitor cells and is the major infectious cause of birth defects in newborns, including sensorineural hearing loss or neuronal migration disturbances during brain development and, in the most severe cases, microcephaly or anencephaly. Previously, we showed that infection of neuronal progenitor cells blocks their ability to differentiate into neurons (29) or astrocytes (30). Interestingly, prevention of the normal differentiation of neuronal stem cells has been implicated as an important step in the early development of brain tumors (31).

We speculate that HCMV infection of a defined tumor precursor cell is a decisive early event in the disordered cerebellar development that leads to medulloblastoma (32) through HCMV-spe- 
A

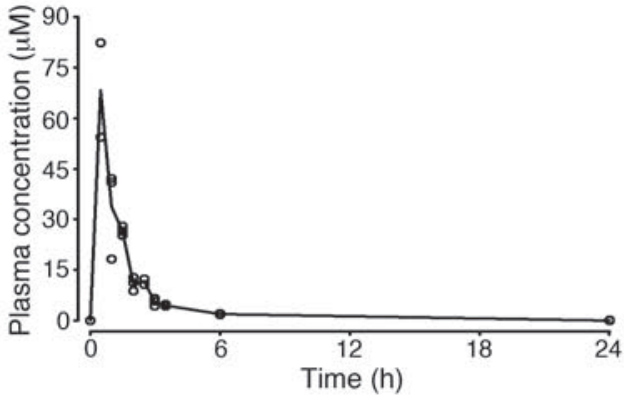

B

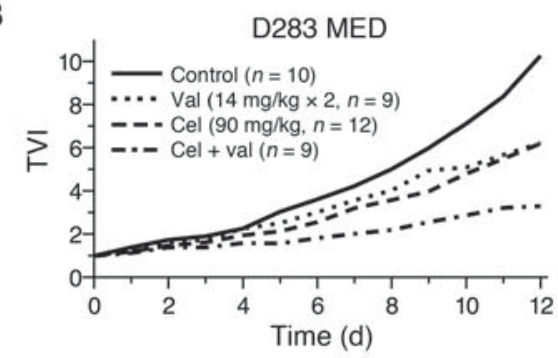

C

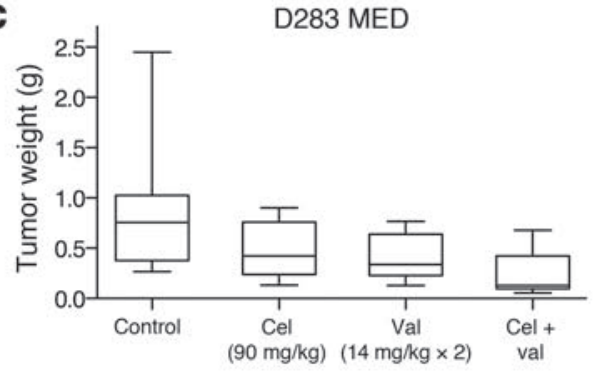

F
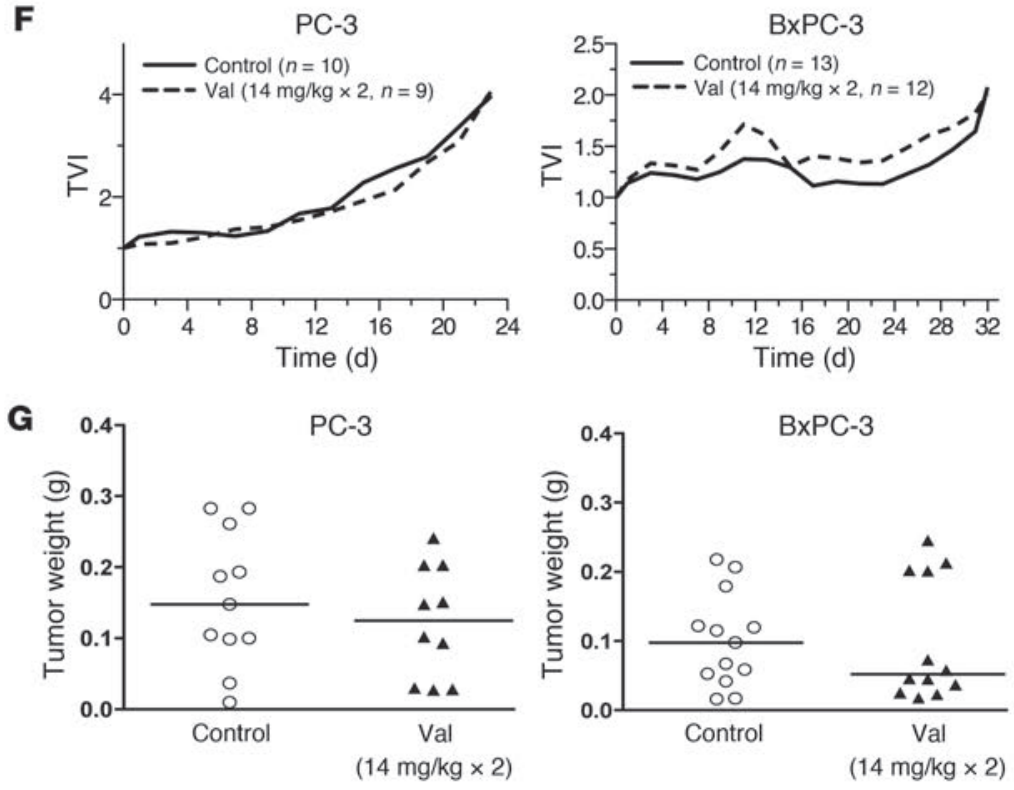

D

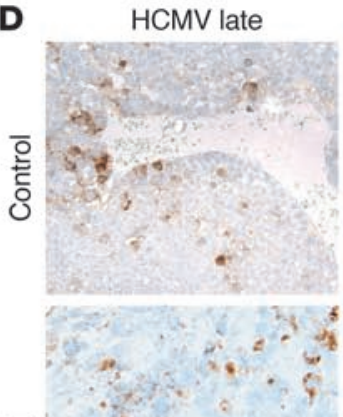

ल

$\overline{\mathcal{D}}$

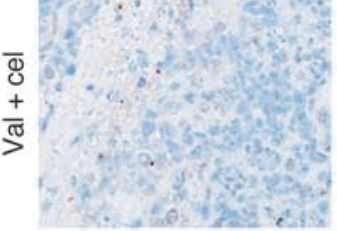

Negative control
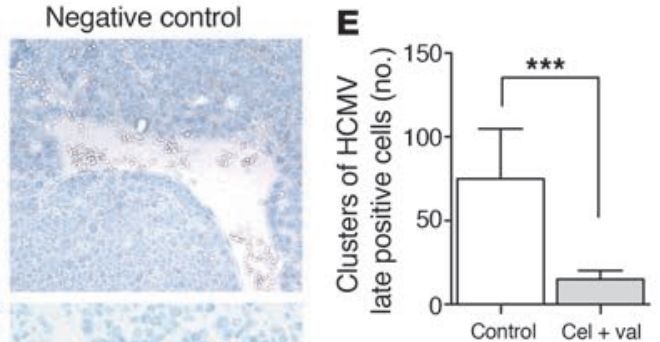

\section{Figure 7}

Ganciclovir and celecoxib significantly impair the growth of established human medulloblastoma xenografts in NMRI nu/nu mice. (A) Pharmacokinetics of valganciclovir (val) (plasma concentration versus time) after 1 oral dose $(100 \mathrm{mg} / \mathrm{kg})$. Solid line represents concentration-time data estimated by pharmacokinetic modeling. NMRI nu/nu mice were engrafted with $7 \times 10^{6}$ D283 MED cells subcutaneously and randomized to receive $14 \mathrm{mg} / \mathrm{kg}$ valganciclovir twice daily, $90 \mathrm{mg} / \mathrm{kg}$ celecoxib daily, both drugs, or no treatment. All treatments were given orally through a gastric feeding tube for 12 days, starting when tumors were $0.1 \mathrm{ml}$ (mean, $0.13 \mathrm{ml}$ ). (B and $\mathbf{C}$ ) Valganciclovir augments the inhibitory effect of celecoxib on medulloblastoma growth in vivo, as shown by the TVI (B) and tumor weight (C) at autopsy. TVI values are mean $\pm S D$; tumor weight is shown as median and quartiles (TVI, 2-tailed ANOVA; tumor weight, 1-way ANOVA). (D and E) Clusters of cells positive for HCMV late protein in xenograft tissues were reduced by $80 \%$ by valganciclovir and celecoxib treatment. Untreated $(n=5), 75 \pm 30$; valganciclovir + celecoxib $(n=7), 15 \pm 5$. Values are mean \pm SD. ${ }^{* * *} P<0.0001$ ( $t$ test). NMRI nu/nu mice were also engrafted subcutaneously with the HCMV-negative cell lines PC-3 $\left(30 \times 10^{6}\right.$ cells $)$ and BxPC-3 $\left(5 \times 10^{6}\right.$ cells $)$ and randomized to receive $14 \mathrm{mg} / \mathrm{kg}$ valganciclovir by gastric feeding twice daily or no treatment for 23 days (PC-3) or 32 days (BxPC-3). (F and $\mathbf{G}$ ) PC-3 or BxPC-3 xenograft growth was not inhibited in mice treated with ganciclovir, as shown by the TVI (F) and tumor weight $(\mathbf{G})$ at autopsy. TVI values are mean \pm SD; tumor weight is shown as median. 
cific effects on tumorigenesis, inflammation, and immune evasion strategies. HCMV infection and expression of US28 result in STAT3 phosphorylation, Wnt activation, enhanced COX-2 expression, production of vascular endothelial growth factor, increased production of $\mathrm{PGE}_{2}$ and IL-6, and inflammation. Transgenic mice (VS28 mice) with US28 expression targeted to intestinal epithelial cells exhibit a hyperplastic intestinal epithelium and develop adenomas and adenocarcinomas at 40 weeks of age (24). When exposed to inflammation, VS28 mice have a significantly higher tumor burden (24). These observations imply that US28 by itself promotes dysplasia and cancer development, especially during enhanced inflammation. HCMV induces inflammation both by its presence as a foreign antigen in tissues and by inducing expression of COX-2 and 5-lipoxygenase, which results in production of prostaglandins and leukotrienes (33). Here, we observed COX-2 expression in HCMV protein-positive cells in primary medulloblastoma samples and in medulloblastoma cell lines, and the induction of COX-2 expression and $\mathrm{PGE}_{2}$ production in experimentally infected medulloblastoma cells. US28 mRNA was detected at 15 minutes and at 1 and 3 hours after infection and before the detection of HCMV IE RNA. It is likely that US28 RNA was delivered with the viral particle, a phenomenon that is known to occur during HCMV infection (34). US28 may also be carried in the virus envelope, and may directly affect COX-2 expression immediately after infection (35). Indeed, we found that induced COX-2 expression was observed in HCMV- and UV-HCMV-infected cells at 1 and 3 hours after infection. We speculate that US28 (protein and RNA) delivered by the virus particle results in the early expression of COX-2 protein, while newly transcribed US28 RNA molecules produced during viral replication were responsible for the induced COX-2 expression at 48 and 72 hours after infection. This statement is substantiated by the observation that COX-2 expression was not increased in cells infected with the UV-treated virus at 48 and 72 hours after infection.

Besides US28, many other factors may facilitate the development of cancer in HCMV-infected individuals. Several HCMVencoded gene products control cellular pathways that could be involved in cancer development, among them cellular differentiation, cell cycle regulation, DNA damage and repair, epigenetic functions, apoptosis, cellular migration, angiogenesis, and immune evasion (9). For example, HCMV provokes chromosomal instability (36), and HCMV IE proteins induce telomerase activity (25) and exert fundamental effects on the cell cycle. HCMV IE86 binds to p53 and controls proliferation, whereas IE72 induces proliferation of cells by dysregulating PI3K/Akt activity, retinoblastoma $(\mathrm{Rb})$ phosphorylation, and expression of p53 family proteins (p53, p63, and p73) (37).

HCMV UL97 phosphorylates the Rb protein and prevents apoptosis (38). Thus, interactions with the $\mathrm{p} 53$ and $\mathrm{Rb}$ families of tumor suppressor proteins will promote cell cycle progression and increase DNA synthesis while simultaneously elongating telomeres and blocking apoptosis (39-42). In primary glioblastomas, we found that mainly HCMV IE-positive cells expressed hTERT, and the HCMV IE72 protein directly interacted with the hTERT promoter at SP1 binding sites to induce telomerase activity and telomere elongation (25). This scenario will most likely be important in tumor transformation.

The two HCMV IE-specific antibodies we used to detect IE proteins in primary medulloblastoma tissue specimens resulted in different staining patterns. The CH160 clone from Abcam recognizes both IE72 and IE86, while the Chemicon antibody recognizes a 68 - to $72-\mathrm{kDa}$ protein, which likely explains the different staining pattern of IE protein expression revealed by direct immunofluorescence and immunohistochemistry. We and others have noted that IE protein is expressed in both the cytoplasm and the nucleus in tumor cells, a pattern that may depend on different IE splicing variants encoded by the IE gene (43).

At the same time as HCMV induces inflammation and may affect tumorigenesis, many HCMV proteins use sophisticated mechanisms that make the infected cells invisible to the immune system. The result is enhanced viral replication and tumor growth. In support of this statement, the viral load in glioblastomas appears to be associated with patient outcome. We recently observed significantly longer median survival in glioblastoma patients with low-grade HCMV infection in the tumor than those with high-grade infections. The 2-year survival rate was also greater in patients with low-grade infections. These findings imply that the HCMV infection level in glioblastomas has a high prognostic value and that HCMV may contribute to the pathogenesis of glioblastoma rather than representing an epiphenomenon of the disease (our unpublished observations).

Targeting HCMV may be a new therapeutic option for medulloblastoma patients. In medulloblastoma cell lines, treatment with ganciclovir markedly reduced the number of HCMV-positive cells but did not eliminate the virus. Furthermore, treatment of medulloblastoma cells with two drugs with different modes of action efficiently inhibited tumor growth in vitro and in vivo. In combination, the drugs reduced tumor growth by $81 \%-97 \%$ in clonogenic assays and by $72 \%$ in NMRI $n u / n u$ mice carrying established human medulloblastoma xenografts. In sharp contrast, ganciclovir had no effect on the clonogenic capacity or tumor growth of two HCMV-negative cell lines (PC-3 and BxPC-3) in vitro or in vivo. Importantly, ganciclovir had no significant toxic or antiproliferative effect on non-tumor cells that were HCMV negative.

These observations imply that the inhibitory effect of ganciclovir on the growth of medulloblastoma cell lines and tumors is HCMV specific and is not mediated by potential nonspecific drug effects on cellular proliferation. Since COX-2 inhibitors efficiently prevent HCMV replication $(22,44)$ and reduce the growth of US28-expressing tumor cells $(21,45)$, the ability of COX-2 inhibitors to protect against cancer in clinical trials may be mediated by control of HCMV replication. Since HCMV has strong oncomodulatory effects, treatment to control HCMV infection in tumor tissues may suppress tumor progression, improve the patient's immune response, and increase the tumor's sensitivity to conventional therapy.

Antiviral drugs for HCMV and COX-2 inhibitors are well tolerated and may be a new therapeutic option to be used in combination with conventional therapies in patients carrying HCMV-infected tumors. Indeed, we are evaluating antiviral drugs against HCMV as an adjuvant therapy for glioblastoma in a double-blind, placebocontrolled pilot study of 42 patients.

In summary, our observations suggest that HCMV is a novel etiological factor linked to medulloblastoma development and that nontoxic antiinflammatory and antiviral drugs targeting HCMV may be used in addition to conventional chemotherapy to treat patients with medulloblastoma.

\section{Methods}

Cell cultures and HCMV. The origin of the cells, culture conditions, and viability assays of human medulloblastoma and supratentorial primitive neuroectodermal cell lines have been described (14). Human prostate cells, 
pancreas adenocarcinoma cells, PC-3 and BxPC- 3 cells, human fibroblasts (MRC-5), and K562 cells (human chronic myelogenous leukemia) were grown in RPMI medium supplemented with $10 \%$ heat-inactivated fetal bovine serum, $2 \mathrm{mM}$ L-glutamine, $100 \mathrm{IU} / \mathrm{ml}$ penicillin $\mathrm{G}$, and $100 \mu \mathrm{g} /$ $\mathrm{ml}$ streptomycin (Life Technologies). Cells were grown to approximately $50 \%-60 \%$ confluence and infected in low-serum medium for the indicated time with HCMV clinical isolate-like strain VR1814 at an MOI of 10. Controls were either not exposed to virus or were exposed to UV-inactivated virus (UV Stratalinker 1800; Stratagene). HCMV VR1814 (provided by G. Gerna, University of Pavia, Pavia, Italy) was prepared from supernatants of cultures of in vitro infected human umbilical vein endothelial cells, grown in EGM2 medium (Clonetics, Cambrex), frozen, and stored at $-70^{\circ} \mathrm{C}$ until use. Viral titers were determined by viral plaque assay (46).

Chemicals. Ganciclovir (Cymevene, Roche) and valganciclovir (Valcyte, Roche) were dissolved in water according to the manufacturer's guidelines. Celecoxib (Pfizer) was dissolved in dimethyl sulfoxide (Sigma-Aldrich). All drugs were further diluted with OptiMEM (Gibco, Invitrogen) to the desired in vitro concentration. Celecoxib for oral administration was prepared as a suspension in $0.5 \%$ methylcellulose (w/v; Sigma-Aldrich) and $0.1 \%$ Tween 80 (v/v; Sigma-Aldrich) in sterile water.

Human medulloblastoma tissue. Human tumor tissue samples were collected and stored at the Department of Oncology and Pathology, Karolinska University Hospital, between 1994 and 2005. Ethical approval was obtained from the Karolinska University Hospital Research Ethics Committee (no. 2008/628-31). The diagnosis of medulloblastoma was confirmed by histological assessment of specimens according to WHO criteria (47). The collection of patient tumor samples from Lund University Hospital was approved by the local ethical board of the University of Lund (no. LU1028$03)$. To protect patient anonymity, tumor samples were de-identified.

Immunohistochemistry/immunofluorescence. Tumor sections were stained for HCMV IE proteins (MAB810, Chemicon; 1:100), late proteins (MAB8127, Chemicon; 1:200), and $\alpha$-actin (Biogenex; 1:100) as described previously (7). Briefly, sections were deparaffinized in xylene, rehydrated in decreasing concentrations of ethanol, ending with water and TBST buffer $(0.9 \% \mathrm{NaCl}$, $0.1 \mathrm{M}$ Tris, $\mathrm{pH} 7.5$, Triton X-100, 2-3 drops/1), and postfixed in $4 \%$ neutral buffered formalin. For retrieval of epitopes, sections were treated with pep$\sin$ (BioGenex) and incubated in citrate buffer (Biogenex). After treatment with $3 \% \mathrm{H}_{2} \mathrm{O}_{2}$ (Sigma-Aldrich) to prevent endogenous peroxidase activity (avidin/biotin blocking kit, Dako) and with Fc receptor blocker and Background Buster (Innovex Biosciences) to prevent nonspecific binding, tissues were incubated with primary antibody at $4{ }^{\circ} \mathrm{C}$ overnight and with secondary anti-mouse antibody at room temperature for 45 minutes (BioGenex). Antibodies were visualized with streptavidin-conjugated horseradish peroxidase and diaminobenzidine (Innovex Biosciences).

Tumor tissue from resected surgical material was snap-frozen in isopentane that had been precooled in liquid nitrogen to $-55^{\circ} \mathrm{C}$. The frozen material was stored at $-80^{\circ} \mathrm{C}$ until sectioning. Tumor tissue was cut into $6-\mu \mathrm{m}$ sections with a cryostat (Leica Microsystems) and placed on glass slides. Slides were dried at room temperature for 30 minutes, wrapped in aluminum foil, and kept at $-80^{\circ} \mathrm{C}$. Tissue sections were thawed for 5 minutes at room temperature, fixed in $4 \%$ paraformaldehyde for 10 minutes, and rinsed in PBS without $\mathrm{Ca}^{2+}$ and $\mathrm{Mg}^{2+}$ (Gibco, Invitrogen). To permeabilize the tissue, PBS containing $0.1 \%$ saponin (Sigma-Aldrich) was used in all washing steps and as diluent. To block nonspecific binding of the secondary antibodies, sections were treated with $5 \%$ goat serum for 20 minutes (Jackson ImmunoResearch Laboratories Inc., Fisher Scientific). Sections were incubated with the primary antibodies for 60 minutes at room temperature. The primary antibodies were mouse monoclonal (CH160) to HCMV IE1 and IE2 $(5 \mu \mathrm{g} / \mathrm{ml})$, mouse monoclonal (CH12) to cytomegalovirus UL83 $(5 \mu \mathrm{g} / \mathrm{ml})$, rabbit polyclonal to COX-2 $(5 \mu \mathrm{g} / \mathrm{ml}$, Abcam), and mouse monoclonal IgG1 isotype control ( $5 \mu \mathrm{g} / \mathrm{ml}$, Acris Antibodies). Sections were rinsed in PBS containing $0.1 \%$ saponin and incubated with the secondary antibodies for 30 minutes at room temperature in the dark. The secondary antibodies were goat anti-mouse Alexa Fluor $594(5 \mu \mathrm{g} / \mathrm{ml})$ and goat anti-rabbit Alexa Fluor $488(5 \mu \mathrm{g} / \mathrm{ml}$, Molecular Probes, Invitrogen). Sections were then rinsed in PBS and mounted wet in ProLong Gold Antifade medium (Molecular Probes, Invitrogen) containing DAPI for nuclear staining. Staining for IE and late proteins was evaluated by grading sections as negative or from 1-4, depending on the estimated percentage of positive cells: $1:<25 \%, 2: 25 \%-50 \%, 3:>50 \%-75 \%, 4:>75 \%$.

Flow cytometry. Resected tumor material was placed in sterile $50-\mathrm{ml}$ tubes containing cell culture medium (UltraCulture, Lonza BioWhittaker-VWR) supplemented with $2 \mathrm{mM}$ L-glutamine (Lonza BioWhittaker-VWR), referred to as UC, at the surgical theater and transported on ice to the cell culture facility. One piece of tumor was cryopreserved for sectioning, and one piece was dissociated into a single-cell suspension for flow cytometric analysis.

For single-cell suspensions, the tumor was cut into small pieces with a sterile scalpel blade in a petri dish containing Accutase (Sigma-Aldrich). The tumor was incubated for 15 minutes at $37^{\circ} \mathrm{C}$. During this time, the tumor was removed once from the incubator and dissociated through a $10-\mathrm{ml}$ serological pipette. After incubation, the tumor was further dissociated by pipetting and transferred to a cell strainer $(75 \mu \mathrm{m})$ (Falcon, BD Biosciences - Pharmingen) on a 50-ml tube. A 2-ml syringe plunger was used to mince the tumor through the cell strainer. Approximately $8 \mathrm{ml} \mathrm{UC}$ was used to rinse the strainer. Cells were centrifuged for 8 minutes at $335 \mathrm{~g}$, resuspended in UC, and counted.

To permeabilize cells for intracellular staining, the Cytofix/Cytoperm kit (BD) was used according to the manufacturer's instructions. Cells were washed twice in PBS without $\mathrm{Ca}^{2+}$ and $\mathrm{Mg}^{2+}$ (Gibco, Invitrogen) supplemented with $1 \%$ bovine serum albumin fraction $V$ (Roche) before the primary antibody was added (mouse monoclonal [CH12] to cytomegalovirus UL83, Abcam) for 60 minutes at $4{ }^{\circ} \mathrm{C}$. Cells were washed as above before incubation with the secondary antibody, FITC-conjugated anti-mouse IgG (eBioscience), for 30 minutes at $4{ }^{\circ} \mathrm{C}$ and washed twice in PBS and $1 \%$ bovine serum albumin fraction $\mathrm{V}$. As negative control, the primary antibody was omitted, and cells were incubated with the secondary antibody only. Cells were analyzed with a flow cytometer (C6, Accuri). Gating for tumor cells was based on forward and side scatter, and data were analyzed with CFlow Plus software (Accuri).

The medulloblastoma cell lines (D324 MED, D283 MED, and UW228-3) were permeabilized with the Perm 2 kit (BD) according to the manufacturer's instructions. The following antibodies were used: mouse monoclonal IgG1 (Dako), IE antigen (mouse monoclonal 11-003, Argene), pp65 (mouse monoclonal, Novocastra), MAB810R (mouse monoclonal, Chemicon), and COX-2 (rabbit polyclonal, Santa Cruz Biotechnology Inc.). The cells were incubated with the primary antibody for 30 minutes at $4^{\circ} \mathrm{C}$, washed with PBS, and incubated for 30 minutes at $4^{\circ} \mathrm{C}$ with the secondary antibody (FITC-conjugated polyclonal rabbit anti-mouse IgG, Dako). For double staining for COX-2 and IE antigen (Argene), cells were incubated with the secondary antibodies FITC-conjugated swine anti-rabbit (Dako) and R-PE-conjugated goat anti-mouse (Jackson ImmunoResearch Laboratories Inc.). After incubation, cells were washed with PBS, fixed with $1 \%$ paraformaldehyde, and analyzed with a CyAn flow cytometer (Beckman Coulter) and Summit 4.3 software.

DNA extraction and HCMV PCR. DNA was extracted from cell pellets with the QIAamp DNA Mini Kit (QIAGEN) according to the manufacturer's protocol. HCMV IE and Pp150 genes were detected by real-time PCR (Invitrogen, Life Technologies) with specific primers (IE: GTGACCCATGTGCTTATGACTCTAT, CTCAACATAGTCTGCAGGAACGT, FAMTTGGTCACGGGTGTCTC; pp150: GGCGCGGGAACCTCTT, CCGT- 
GGGCGACAAAACG, FAM-CAGCCGTCAGCCTCG). The housekeeping gene RnasP served as a control (Applied Biosystems).

Quantitative PCR. D324 MED cells were seeded in 6-well plates (Sarstedt) at $1 \times 10^{6}$ cells/well and superinfected with HCMV VR1814 (MOI of 10) in low-serum medium. Cells were collected 15 minutes and 1, 3, 6, 24, 48, and 72 hours after infection and frozen at $-80^{\circ} \mathrm{C}$ before RNA extraction with the RNeasy RNA kit (QIAGEN). cDNA was synthesized from equal amounts of RNA with the SuperScript III First-Strand Synthesis System (Invitrogen, Life Technologies). cDNA was then used for quantitative PCR for HCMV IE, pp150, US28, and COX-2 with TaqMan gene expression assays (Applied Biosystems). RnasP, $\beta$ - 2 microglobulin, and $\beta$-actin (Applied Biosystems) served as controls. Each experiment was performed in duplicate and repeated 3 times.

In situ bybridization. HCMV DNA in paraffin sections was detected as described previously (5) with minor modifications. Fluorescein-labeled HCMV total genome DNA probe (Zymed, Invitrogen) was denatured on paraffin sections with a MISHA thermocycler (Shandon Lipshaw), and slides were hybridized overnight at $37^{\circ} \mathrm{C}$ in a humidified chamber. Specific endogenous Alu DNA sequence and nonspecific DNA-labeled control fluorescein probes provided by the manufacture (Zymed, Invitrogen) served as positive and negative controls, respectively. Probes were detected by using alkaline phosphatase-labeled antibodies against fluorescein (Zymed, Invitrogen) and Fast Red chromogen (BioGenex).

FISH. For probe preparation, a plasmid containing the whole HCMV genome (provided by J. Nelson, Oregon Health \& Science University, Portland, Oregon, USA) was labeled with a Nick Translation Kit (Vysis) according to the manufacturer's recommendations. For slide preparation, cells were treated with colcemid $\left(10 \mu \mathrm{g} / \mathrm{ml}\right.$, Invitrogen) for 30 minutes at $37^{\circ} \mathrm{C}$ and washed with HBSS (Invitrogen). The cell pellet was resuspended in cold $0.56 \% \mathrm{KCl}$ (Sigma-Aldrich) and incubated for 10 minutes at $37^{\circ} \mathrm{C}$. Cells (D283 MED and D324 MED medulloblastoma cells, K562 cells, or in vitro infected fibroblasts) were collected by centrifugation. Cold fixation solution (3:1 methanol/acetic acid) was gently added to the cell suspension and centrifuged. Fixed cells were washed, resuspended in fixation solution, and stored at $20^{\circ} \mathrm{C}$ before use. Three microliters of cell suspension and one drop of acetic acid/methanol fixative were used for slide preparation. Approximately $400 \mathrm{ng} / \mu \mathrm{l} \mathrm{HCMV}$ probe was added to $2 \mu \mathrm{l}$ hybridization mixture (Invitrogen), $2 \mu \mathrm{l}$ Cot-1 DNA (Invitrogen), $1 \mu \mathrm{l} 0.5 \mathrm{M}$ sodium acetate, $\mathrm{pH} 5.2$, and $30 \mu \mathrm{l}$ ethanol (95\%) and was incubated on dry ice for $15 \mathrm{~min}$ utes and centrifuged. The probe was washed in $70 \%$ ethanol, diluted in $8 \mu \mathrm{l}$ Hybridizol (Invitrogen), added to slides, denatured at $72^{\circ} \mathrm{C}$ for 8 minutes, and incubated overnight at $37^{\circ} \mathrm{C}$. Slides were washed in $2 \times$ saline sodium citrate for 3 minutes at $72^{\circ} \mathrm{C}$, dehydrated, and mounted with VECTASHIELD (Immunkemi, Vector Laboratories).

Immunoblotting. Total cell protein lysates were extracted from cells in RIPA buffer (25 mM Tris, pH 7.8, 2 mM EDTA, 20\% glycerol, 0.1\% Nonidet P-40, $1 \mathrm{mM}$ dithiothreitol). All protein extraction buffers were supplemented with Mini Complete protease inhibitor cocktail (Roche Diagnostics), $1 \mathrm{mmol} / \mathrm{l}$ $\mathrm{NaF}$, and $1 \mathrm{mmol} / \mathrm{I} \mathrm{NaO}_{3} \mathrm{~V}_{4}$. Protein concentration was measured with the Bradford reagent (Bio-Rad). Equal quantities were separated by SDS-PAGE, transferred to nylon membranes (Millipore), and probed with antibodies against HCMV IE (Argene; 1:200), COX-2 (Santa Cruz Biotechnology Inc.; 1:500), and $\beta$-actin (Sigma-Aldrich; 1:1,000). The secondary antibodies were anti-mouse or anti-rabbit IgG conjugated with horseradish peroxidase (GE Healthcare). Pierce SuperSignal was used to detect chemiluminescence.

$P G E_{2}$ measurement. D324 MED cells were seeded in 96-well plates and cultivated in OptiMEM containing $20 \mu \mathrm{M}$ arachidonic acid (Sigma-Aldrich). Cells were infected with HCMV VR1814 (MOI of 10) or treated with increasing concentrations of ganciclovir $(75-150 \mu \mathrm{M})$, celecoxib $(2.5-10 \mu \mathrm{M})$, or both drugs for 72 hours. Cell supernatants were harvested, and $\mathrm{PGE}_{2}$ levels were measured with a $\mathrm{PGE}_{2}$ enzyme-linked immunosorbent assay kit (Cayman Chemicals), according to the manufacturer's instructions.

Clonogenic and MTT assay. Viability assays (MTT) were as described previously (14). Tumorigenic potential was assessed with an in vitro clonogenic assay as described (14). Briefly, cells were infected with HCMV VR1814 (MOI of 10) for 3 days and reseeded in triplicate at 150 cells/well in $50-\mathrm{mm}^{2}$ well $\mathrm{Cell}^{+}$plates (Sarstedt); control cells were not infected. Cells were allowed to attach for 5 hours and treated with ganciclovir $(37.5,75$, or $150 \mu \mathrm{M})$, celecoxib $(5,10$, or $15 \mu \mathrm{M})$, or both drugs for 48 hours. PC- 3 and BxPC- 3 cells were treated with $37.5,75$, and $150 \mu \mathrm{M}$ ganciclovir or left untreated. After 8-12 days of incubation in drug-free medium, cell cultures were rinsed with PBS, fixed in formaldehyde, and stained with Giemsa (Gibco, Invitrogen). Colonies (>75 cells) with $50 \%$ plating efficiency were counted manually. Since D283 MED cells grow as suspension cells, colony formation was assayed in soft agar. Base agar was made by boiling $0.7 \%$ agar (Life Technologies) in minimum essential medium ( $2 \mathrm{mM}$ L-glutamine, $100 \mathrm{IU} / \mathrm{ml}$ penicillin $\mathrm{G}$, and $100 \mu \mathrm{g} / \mathrm{ml}$ streptomycin). The agar was cooled to $40^{\circ} \mathrm{C}$ in a water bath before plating in petri dishes. Top agar was made by boiling $0.35 \%$ agar in the same medium as above. Heat-inactivated fetal bovine serum (15\%) was added to the mixture before cells, pretreated for 48 hours, were added to the base agar. After 20 days of incubation, colonies were manually counted. For each treatment, the surviving fraction was calculated as the ratio of the mean plating efficiency of treated cells to that of untreated controls.

Xenografts and in vivo administration of valganciclovir and celecoxib. Four- to 6-week-old female NMRI $n u / n u$ mice (Taconic) were maintained at 5 per cage and given sterile water and food ad libitum. Each mouse was subcutaneously injected with $7 \times 10^{6}$ human D283 MED medulloblastoma cells on the flank. When the tumor volumes were greater than $0.1 \mathrm{ml}$ (mean tumor volume at the start of treatment, $0.13 \mathrm{ml}$ ), the mice were randomly assigned to 4 groups: $14 \mathrm{mg} / \mathrm{kg}$ valganciclovir twice daily $(n=9), 90 \mathrm{mg} / \mathrm{kg}$ celecoxib daily $(n=12), 90 \mathrm{mg} / \mathrm{kg}$ celecoxib daily and $14 \mathrm{mg} / \mathrm{kg}$ valganciclovir twice daily $(n=9)$, or no treatment $(n=10)$; the drugs were given orally through a gastric feeding tube. As a control for the effect of valganciclovir on cellular proliferation, we established xenografts of two HCMV-negative cell lines $\left(30 \times 10^{6} \mathrm{PC}-3\right.$ cells or $5 \times 10^{6} \mathrm{BxPC}-3$ cells in each mouse $)$ in NMRI $n u / n u$ mice and treated the animals with a similar dose of valganciclovir $(14$ $\mathrm{mg} / \mathrm{kg}$ ). Each mouse was treated for 23 (PC-3) or 32 (BxPC-3) consecutive days. The mean tumor volume at the start of treatment was $0.13 \mathrm{ml}$ (PC-3) or $0.15 \mathrm{ml}$ (BxPC-3). Tumors were measured daily, and tumor volume was calculated as (width) $)^{2} \times$ length $\times 0.44$. At autopsy, tumors were weighed, dissected in smaller parts, and either snap frozen in liquid nitrogen or fixed in formaldehyde for immunohistochemical analysis. The TVI was calculated as the measured volume divided by the volume measured at the start of treatment. All animal experiments were approved by the regional ethics committee for animal research (approval N304/08) in accordance with the Swedish Animal Protection Law (SFS 1988:534), the Animal Protection Regulation (SFS 1988:539), and the Regulation for the Swedish National Board for Laboratory Animals (SFS 1988:541).

Statistics. All statistical analyses were performed with GraphPad Prism software (GraphPad Software). For in vitro studies, the $t$ test (2-tailed) was used to determine whether the mean of a single sample differed significantly from control. To compare several treatment groups, 1-way ANOVA with Tukey multiple-comparisons tests were used. A $P$ value less than 0.05 was considered significant. Tumor growth was analyzed by unpaired, 2-tailed ANOVA and tumor weight by 1-way ANOVA; for both, the Bonferroni post hoc test was used for multiple comparisons between groups.

\section{Acknowledgments}

This work was supported by grants from Torsten and Ragnar Söderberg's Foundations, Swedish Children's Cancer Foundation, 
Swedish Cancer Society, Swedish Research Council, Märta and Gunnar V. Philipson Foundation, Mary Bevé Foundation, Hans and Märit Rausing Charitable Fund, Dämman Foundation, Swedish Society for Medical Research (SLS), Goljes Memory Foundation, Magnus Bergvalls Foundation, Swedish Society for Medical Research (SSMF), and Tore Nilsons Foundation. We thank Stephen Ordway for editing the manuscript.

Received for publication January 24, 2011, and accepted in revised form July 13, 2011.
Address correspondence to: Cecilia Söderberg-Nauclér, Center for Molecular Medicine, L8:03, Cell and Molecular Immunology, Karolinska Institutet, Karolinska University Hospital, SE-171 76 Stockholm, Sweden. Phone: 46851779896; Fax: 468313147; E-mail: cecilia.naucler@ki.se. Or to: John Inge Johnsen, Karolinska Institutet, Childhood Cancer Research Unit, Q6:05, Department of Women's and Children's Health, Karolinska Institutet, Stockholm 17176, Sweden. Phone: 46851772989; Fax: 48851773475; E-mail: John.Inge.Johnsen@ki.se.
1. Thompson MC, et al. Genomics identifies medulloblastoma subgroups that are enriched for specific genetic alterations. J Clin Oncol. 2006; 24(12):1924-1931.

2. Mulhern RK, Merchant TE, Gajjar A, Reddick WE, Kun LE. Late neurocognitive sequelae in survivors of brain tumours in childhood. Lancet Oncol. 2004;5(7):399-408.

3. Rood BR, Macdonald TJ, Packer RJ. Current treatment of medulloblastoma: recent advances and future challenges. Semin Oncol. 2004;31(5):666-675.

4. Parsons DW, et al. The genetic landscape of the childhood cancer medulloblastoma. Science. 2011; 331(6016):435-439.

5. Cobbs CS, et al. Human cytomegalovirus infection and expression in human malignant glioma. Cancer Res. 2002;62(12):3347-3350.

6. Harkins L, et al. Specific localisation of human cytomegalovirus nucleic acids and proteins in human colorectal cancer. Lancet. 2002;360(9345):1557-1563.

7. Samanta M, Harkins L, Klemm K, Britt WJ, Cobbs CS. High prevalence of human cytomegalovirus in prostatic intraepithelial neoplasia and prostatic carcinoma. J Urol. 2003;170(3):998-1002.

8. Michaelis M, Doerr HW, Cinatl J Jr. Oncomodulation by human cytomegalovirus: evidence becomes stronger. Med Microbiol Immunol. 2009;198(2):79-81.

9. Soroceanu L, Cobbs CS. Is HCMV a tumor promoter? Virus Res. 2011;157(2):193-203.

10. Powers C, DeFilippis V, Malouli D, Fruh K. Cytomegalovirus immune evasion. Curr Top Microbiol Immunol. 2008;325:333-359.

11. Wang D, Dubois RN. Eicosanoids and cancer. Nat Rev Cancer. 2010;10(3):181-193.

12. Mrena J, et al Cyclooxygenase- 2 is an independent prognostic factor in gastric cancer and its expression is regulated by the messenger RNA stability factor HuR. Clin Cancer Res. 2005;11(20):7362-7368.

13. Soumaoro LT, Uetake H, Higuchi T, Takagi Y, Enomoto M, Sugihara K. Cyclooxygenase-2 expression: a significant prognostic indicator for patients with colorectal cancer. Clin Cancer Res. 2004; 10(24):8465-8471.

14. Baryawno N, et al. Tumor-growth-promoting cyclooxygenase- 2 prostaglandin E2 pathway provides medulloblastoma therapeutic targets. Neuro Oncol. 2008;10(5):661-674.

15. Thun MJ, Henley SJ, Patrono C. Nonsteroidal antiinflammatory drugs as anticancer agents: mechanistic, pharmacologic, and clinical issues. $J$ Natl Cancer Inst. 2002;94(4):252-266.

16. Elwood PC, Gallagher AM, Duthie GG, Mur LA, Morgan G. Aspirin, salicylates, and cancer. Lancet. 2009;373(9671):1301-1309

17. Rothwell PM, Fowkes FG, Belch JF, Ogawa H, Warlow CP, Meade TW. Effect of daily aspirin on long- term risk of death due to cancer: analysis of individual patient data from randomised trials. Lancet. 2011;377(9759):31-41.

18. Wang L, Chen W, Xie X, He Y, Bai X. Celecoxib inhibits tumor growth and angiogenesis in an orthotopic implantation tumor model of human colon cancer. Exp Oncol. 2008;30(1):42-51.

19. Cuzick J, et al. Aspirin and non-steroidal antiinflammatory drugs for cancer prevention: an international consensus statement. Lancet Oncol. 2009; 10(5):501-507.

20. Bosetti C, Gallus S, La Vecchia C. Aspirin and cancer risk: a summary review to 2007 . Recent Results Cancer Res. 2009;181:231-251.

21. Maussang D, et al. The human cytomegalovirusencoded chemokine receptor US28 promotes angiogenesis and tumor formation via cyclooxygenase- 2 . Cancer Res. 2009;69(7):2861-2869.

22. Speir E, Yu ZX, Ferrans VJ, Huang ES, Epstein SE. Aspirin attenuates cytomegalovirus infectivity and gene expression mediated by cyclooxygenase- 2 in coronary artery smooth muscle cells. Circ Res. 1998; 83(2):210-216.

23. Zhu H, Cong JP, Yu D, Bresnahan WA, Shenk TE. Inhibition of cyclooxygenase 2 blocks human cytomegalovirus replication. Proc Natl Acad Sci U S A. 2002;99(6):3932-3937.

24. Bongers $\mathrm{G}$, et al. The cytomegalovirus-encoded chemokine receptor US28 promotes intestinal neoplasia in transgenic mice. J Clin Invest. 2010; 120(11):3969-3978.

25 . Straat K, et al. Activation of telomerase by human cytomegalovirus. J Natl Cancer Inst. 2009;101(7):488-497.

26. Baryawno N, Sveinbjornsson B, Kogner P, Johnsen JI. Medulloblastoma: a disease with disorganized developmental signaling cascades. Cell Cycle. 2010;9(13):2548-2554

27. Read TA, et al. Identification of CD15 as a marker for tumor-propagating cells in a mouse model of medulloblastoma. Cancer Cell. 2009;15(2):135-147.

28. Singh SK, et al. Identification of human brain tumour initiating cells. Nature. 2004;432(7015):396-401.

29. Odeberg J, Wolmer N, Falci S, Westgren M, Seiger A, Soderberg-Naucler C. Human cytomegalovirus inhibits neuronal differentiation and induces apoptosis in human neural precursor cells. J Virol. 2006; 80(18):8929-8939.

30. Odeberg J, et al. Late human cytomegalovirus (HCMV) proteins inhibit differentiation of human neural precursor cells into astrocytes. J Neurosci Res. 2007;85(3):583-593.

31. Sanai N, Alvarez-Buylla A, Berger MS. Neural stem cells and the origin of gliomas. N Engl J Med. 2005; 353(8):811-822.

32. Scotting PJ, Walker DA, Perilongo G. Childhood solid tumours: a developmental disorder. Nat Rev
Cancer. 2005;5(6):481-488

33. Qiu H, Straat K, Rahbar A, Wan M, SoderbergNaucler C, Haeggstrom JZ. Human CMV infection induces 5-lipoxygenase expression and leukotriene B4 production in vascular smooth muscle cells. J Exp Med. 2008;205(1):19-24.

34. Bresnahan WA, Shenk T. A subset of viral transcripts packaged within human cytomegalovirus particles. Science. 2000;288(5475):2373-2376.

35. Zipeto D, Bodaghi B, Laurent L, Virelizier JL, Michelson S. Kinetics of transcription of human cytomegalovirus chemokine receptor US28 in different cell types. J Gen Virol. 1999;80(pt 3):543-547.

36. Fortunato EA, Dell'Aquila ML, Spector DH. Specific chromosome 1 breaks induced by human cytomegalovirus. Proc Natl Acad Sci U S A. 2000;97(2):853-858.

37. Cobbs CS, Soroceanu L, Denham S, Zhang W, Kraus MH. Modulation of oncogenic phenotype in human glioma cells by cytomegalovirus IE1-mediated mitogenicity. Cancer Res. 2008;68(3):724-730.

38. Hume AJ, Finkel JS, Kamil JP, Coen DM, Culbertson MR, Kalejta RF. Phosphorylation of retinoblastoma protein by viral protein with cyclin-dependent kinase function. Science. 2008;320(5877):797-799.

39. Zhu H, Shen Y, Shenk T. Human cytomegalovirus IE1 and IE2 proteins block apoptosis. J Virol. 1995;69(12):7960-7970

40. Yu Y, Alwine JC. Human cytomegalovirus major immediate-early proteins and simian virus 40 large $\mathrm{T}$ antigen can inhibit apoptosis through activation of the phosphatidylinositide 3'-OH kinase pathway and the cellular kinase Akt. J Virol. 2002;76(8):3731-3738.

41. Poma EE, Kowalik TF, Zhu L, Sinclair JH, Huang ES. The human cytomegalovirus IE1-72 protein interacts with the cellular $\mathrm{p} 107$ protein and relieves $\mathrm{p} 107$-mediated transcriptional repression of an E2F-responsive promoter. J Virol. 1996;70(11):7867-7877.

42. Castillo JP, Kowalik TF. Human cytomegalovirus immediate early proteins and cell growth control. Gene. 2002;290(1-2):19-34.

43. Awasthi S, Isler JA, Alwine JC. Analysis of splice variants of the immediate-early 1 region of human cytomegalovirus. J Virol. 2004;78(15):8191-8200.

44. Zhu H, Cong JP, Yu D, Bresnahan WA, Shenk TE. Inhibition of cyclooxygenase 2 blocks human cytomegalovirus replication. Proc Natl Acad Sci U S A. 2002;99(6):3932-3937.

45. Maussang D, et al. Human cytomegalovirus-encoded chemokine receptor US28 promotes tumorigenesis. Proc Natl Acad Sci U S A. 2006;103(35):13068-13073.

46. Wentworth BB, French L. Plaque assay of cytomegalovirus strains of human origin. Proc Soc Exp Biol Med. 1970;135(2):253-258.

47. Kleihues $\mathrm{P}$, et al. The WHO classification of tumors of the nervous system. J Neuropathol Exp Neurol. 2002;61(3):215-225. 